\title{
Nitride Fuel Modeling Recommendation for Nitride Fuel Material Property Measurement Priority
}

\author{
William Carmack
}

Richard Moore

Marya Morison

September 2005

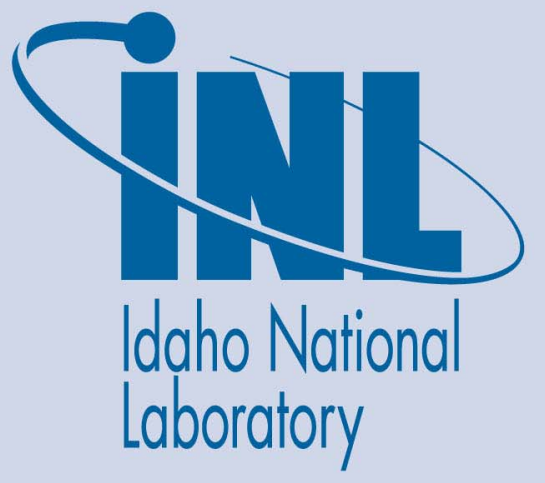

The INL is a U.S. Department of Energy National Laboratory operated by Battelle Energy Alliance 


\title{
Nitride Fuel Modeling Recommendation for Nitride Fuel Material Property Measurement Priority
}

\author{
William Carmack \\ Richard Moore \\ Marya Morison
}

September 2005

Idaho National Laboratory
Idaho Falls, Idaho 83415

Prepared for the

U.S. Department of Energy

Office of Nuclear Energy

Under DOE Idaho Operations Office

Contract DE-AC07-05ID14517 


\begin{abstract}
The purpose of this effort was to provide the basis for a model that effectively predicts nitride fuel behavior. Material property models developed for the uranium nitride fuel system have been used to approximate the general behavior of nitride fuels with specific property models for the transuranic nitride fuels utilized as they become available. The AFCI fuel development program now has the means for predicting the behavior of the transuranic nitride fuel compositions. The key data and models needed for input into this model include:
\end{abstract}

- Thermal conductivity with burnup

- Fuel expansion coefficient

- $\quad$ Fuel swelling with burnup

- $\quad$ Fission gas release with burnup.

Although the fuel performance model is a fully functional FEA analysis tool, it is limited by the input data and models. 


\section{CONTENTS}

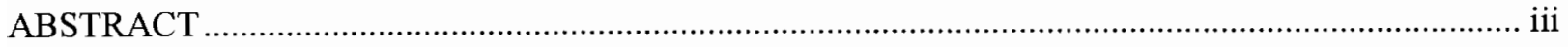

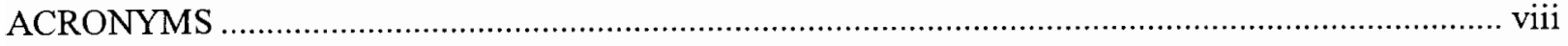

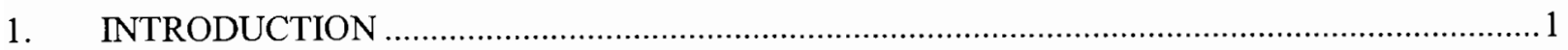

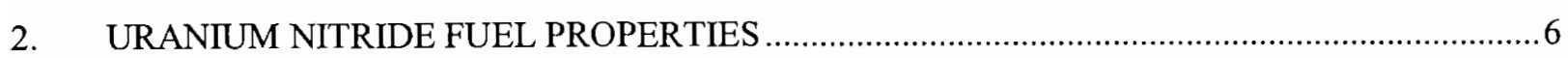

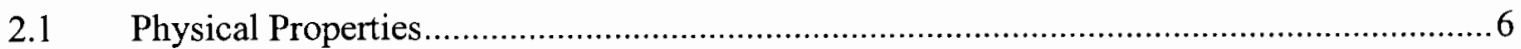

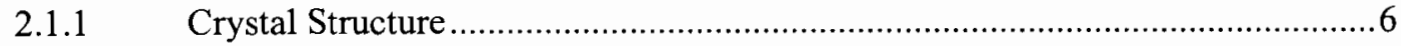

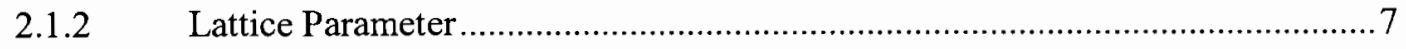

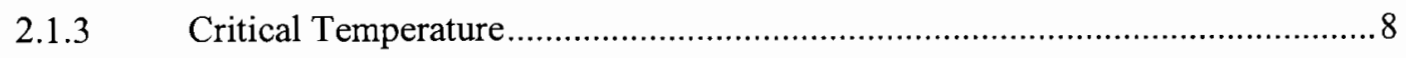

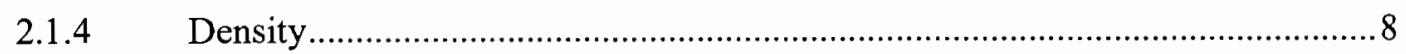

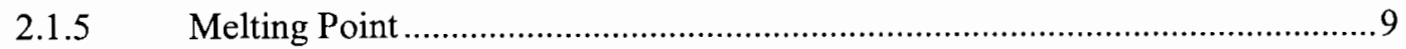

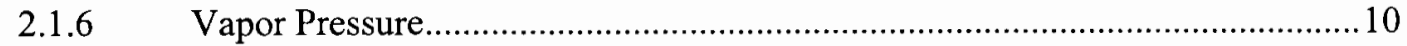

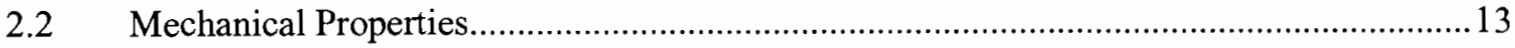

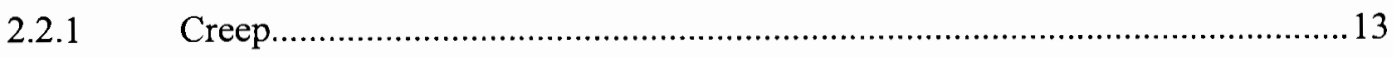

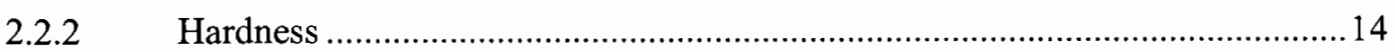

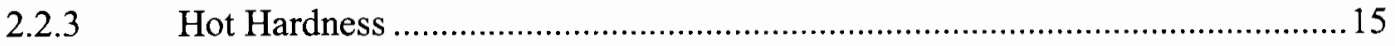

2.2.4 Modulus of Elasticity (Young's Modulus) .....................................................

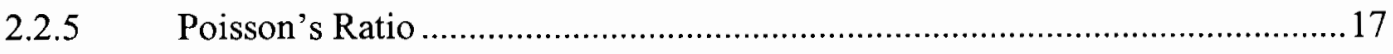

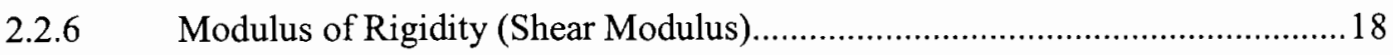

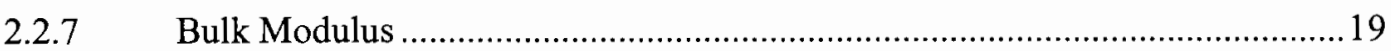

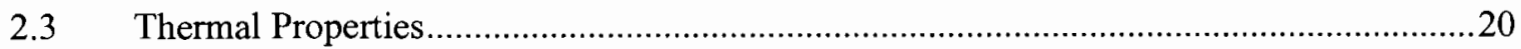

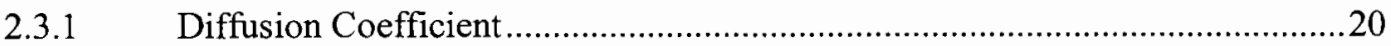

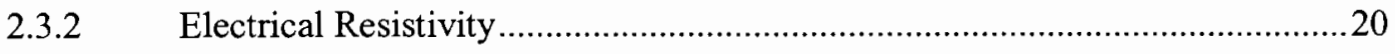

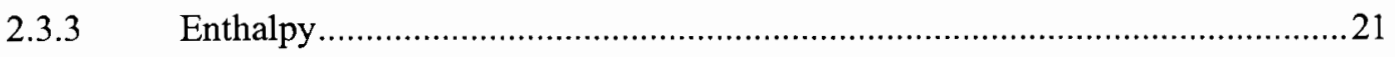

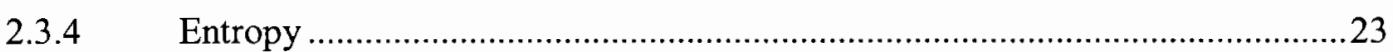

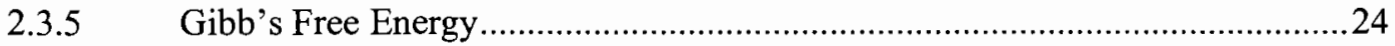

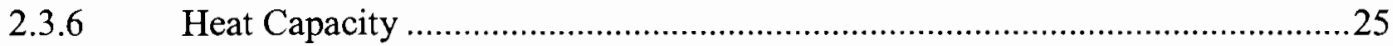

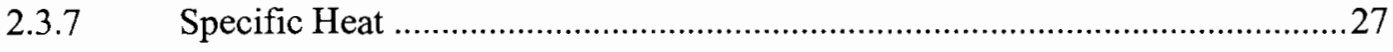

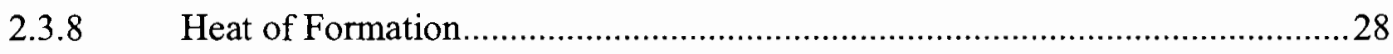

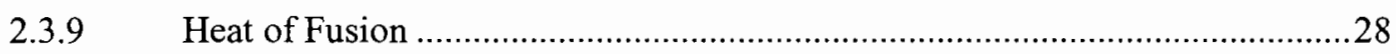

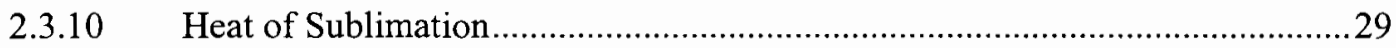

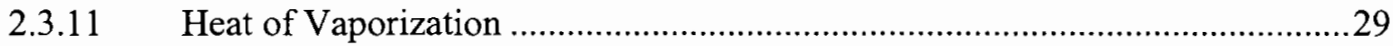

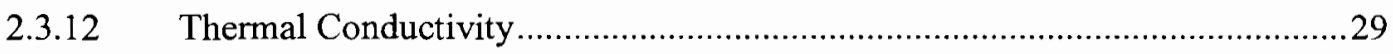

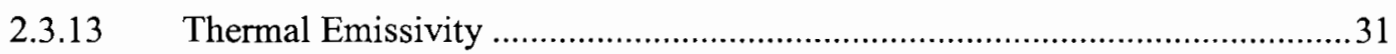

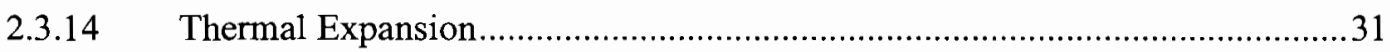

2.3.15 Instantaneous Coefficient of Thermal Expansion........................................ 32 


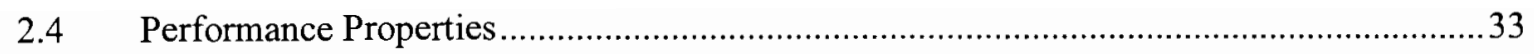

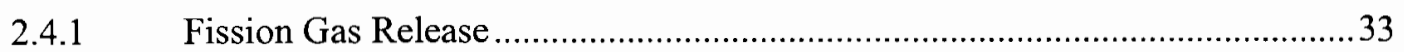

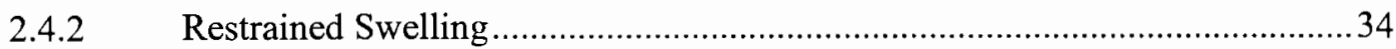

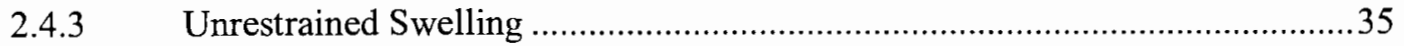

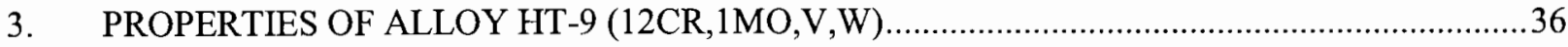

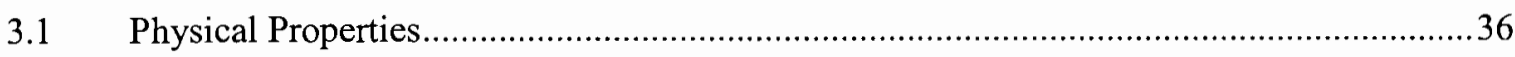

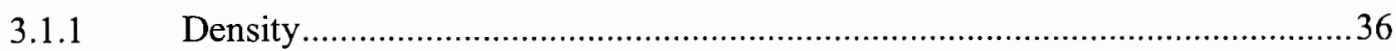

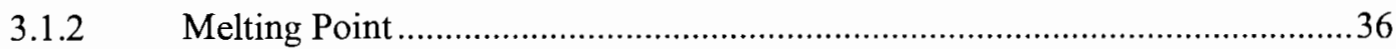

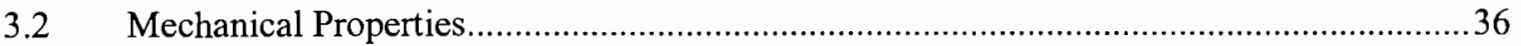

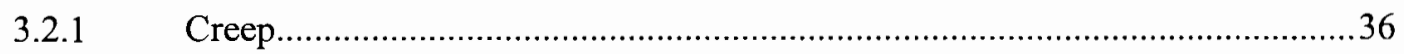

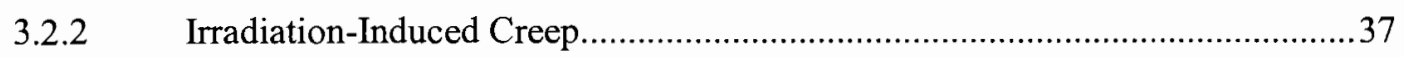

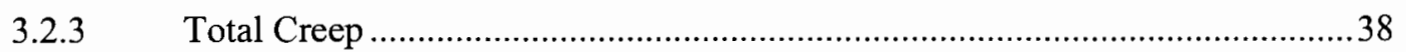

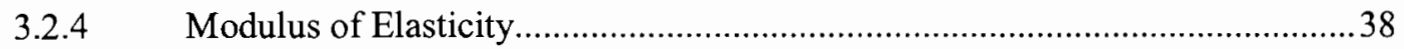

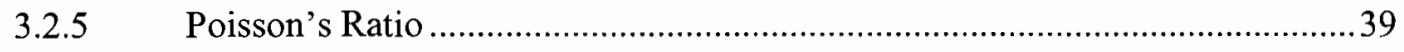

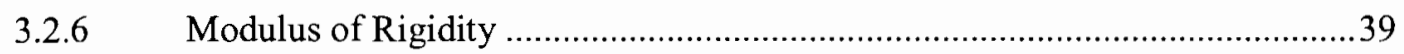

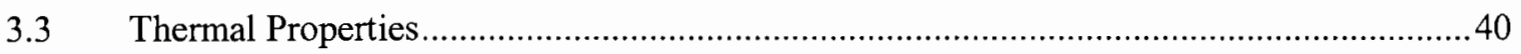

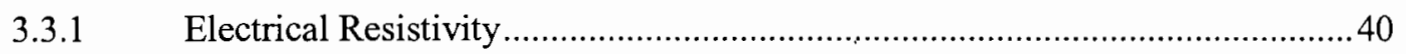

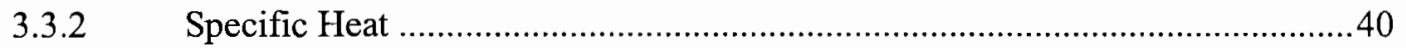

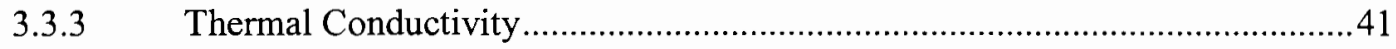

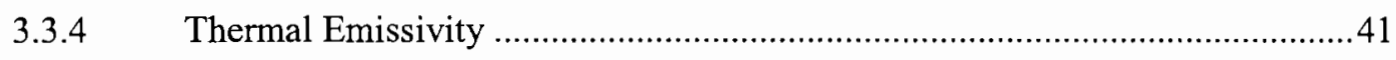

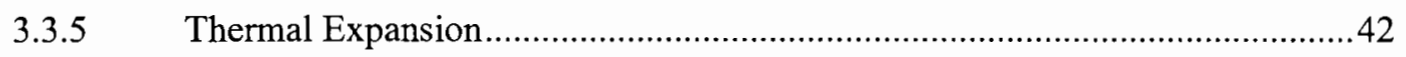

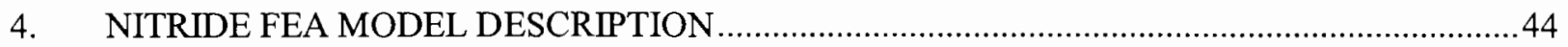

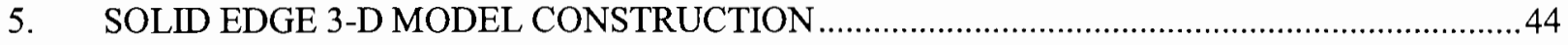

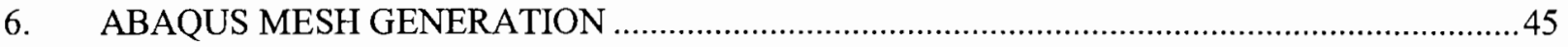

7. ABAQUS MATERIAL PROPERTY SUBROUTINES.......................................................... 47

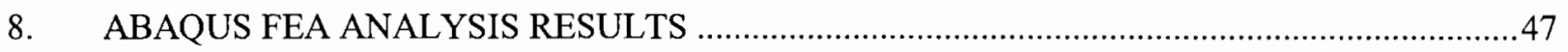

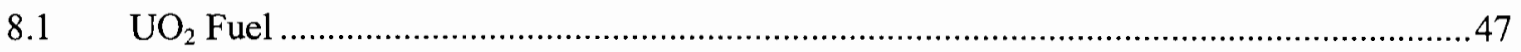

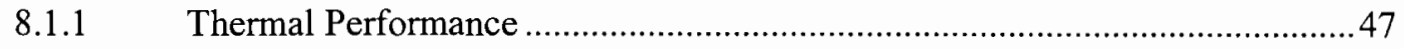

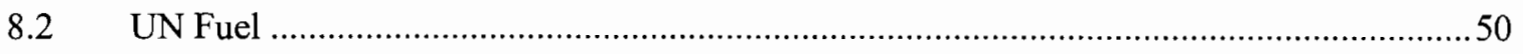

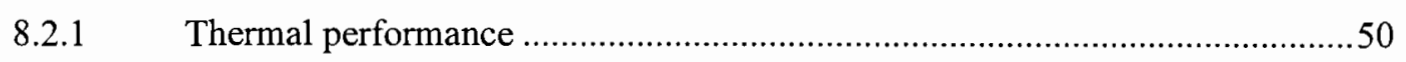

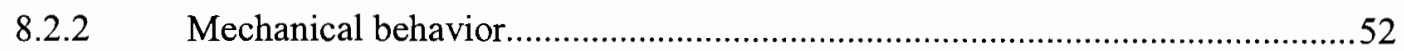

8.3 Discussion of Weaknesses in Material Property Data Base Relative to the Fuel Behavior

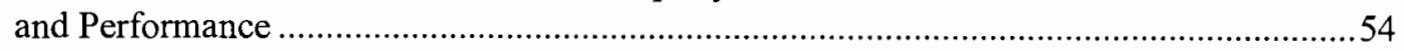

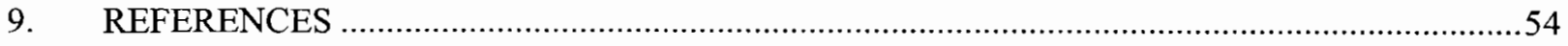

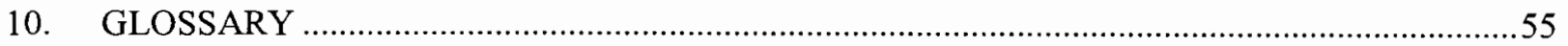




\section{FIGURES}

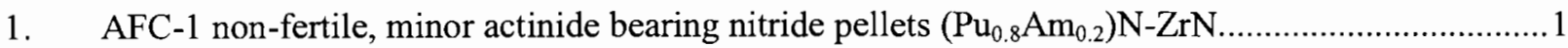

2. Radial dimensions of capsule and fuel rodlet assemblies for nitride fuel rodlet. ...........................2

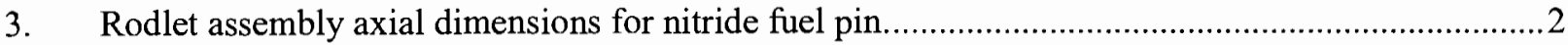

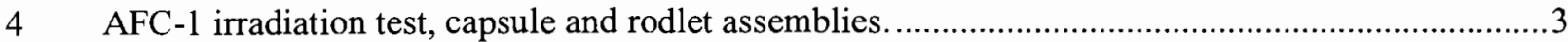

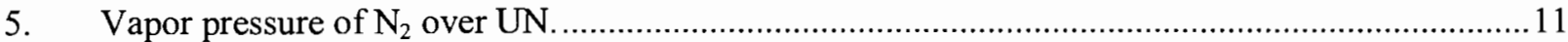

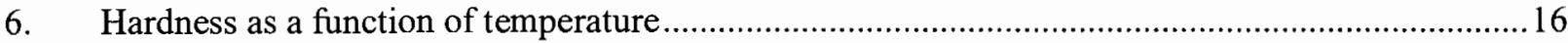

7. Percent release as a function of temperature for 5\% Burnup and 95\% TD ................................34

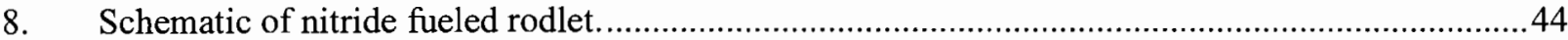

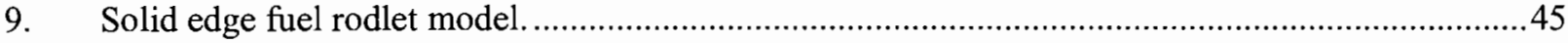

10. Finite element mesh of assembled fuel rodlet and fuel assembly with the cladding and

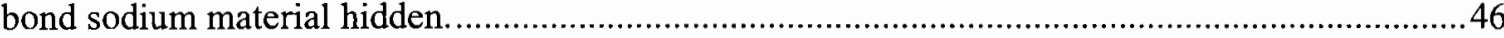

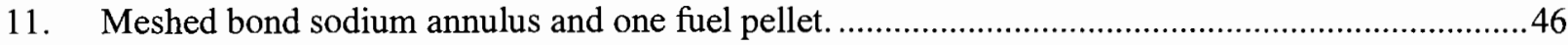

12. A 2D UO $\mathrm{O}_{2}$ Fuel Rod (wedge) modeled in FEMLAB for comparison with exact solution ..............48

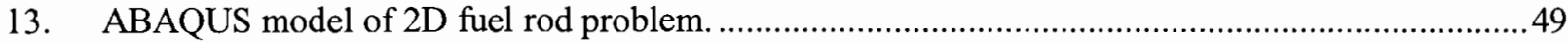

14. Radial temperature profile through $\mathrm{UO}_{2}$ fuel rod. ...............................................................5

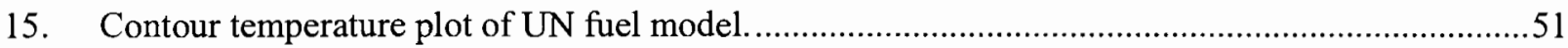

16. Radial temperature profile through UN fuel rodlet.................................................................51

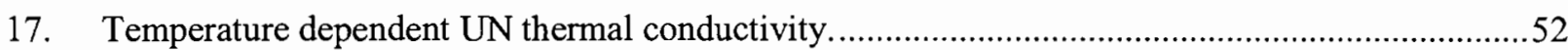

18. Uranium Nitride temperature dependent thermal expansion coefficient. ......................................53

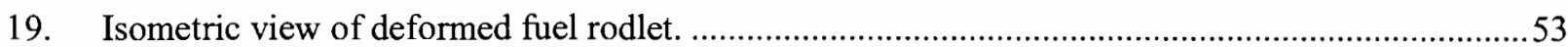

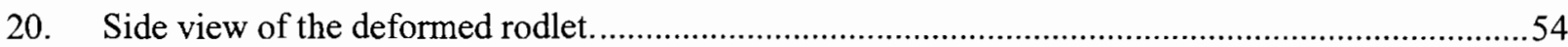

\section{TABLES}

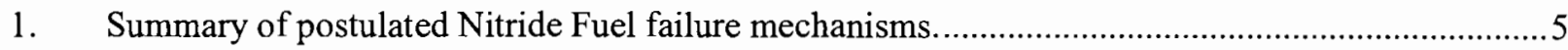

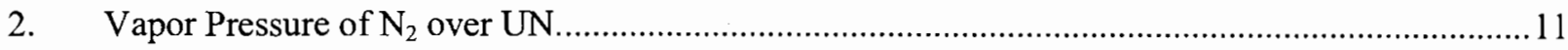

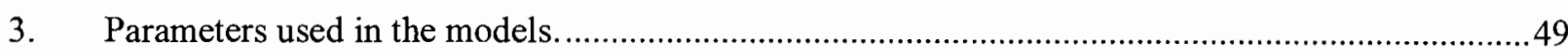




\section{ACRONYMS}

$\begin{array}{ll}\text { AFCI } & \text { Advance Fuel Cycle Initiative } \\ \text { ATR } & \text { Advanced Test Reactor } \\ \text { LANL } & \text { Los Alamos National Laboratory } \\ \text { MOX } & \text { mixed oxide } \\ \text { UN } & \text { Uranium Nitride }\end{array}$




\section{Nitride Fuel Modeling Recommendation for Nitride Fuel Material Property Measurement Priority}

\section{INTRODUCTION}

The Advance Fuel Cycle Initiative (AFCI) fuel development program is currently researching and developing nitride fuel compositions for use in future fast spectrum reactor systems. These compositions will provide the fuel for fast-spectrum reactor systems of the future. The fuel composition designs incorporate the addition of americium and neptunium to reduce the amount of transuranics generated in the fuel cycle and ultimately needing storage in a high level waste repository. Irradiation of Nitride and Metallic Fuels for Actinide Transmutation in the Advanced Test Reactor: Final Experiment Description and Design and Data Package for AFC-1A, AFC-1B, AFC-1C, and AFC-1D details the description of the AFC-1 test series [Ref. 1]. The test series will provide irradiation performance data on non-fertile, actinide transmutation fuel forms containing plutonium, neptunium and americium isotopes. There will six nitride fuel compositions $\left(\mathrm{Pu}_{0.2}, \mathrm{Am}_{0.8}\right) \mathrm{N}-36 \mathrm{ZrN},\left(\mathrm{Pu}_{0.8}, \mathrm{Am}_{0.2}\right) \mathrm{N}-36 \mathrm{ZrN},\left(\mathrm{Pu}_{0.5}, \mathrm{~Np} \mathrm{p}_{0.5}\right) \mathrm{N}-36 \mathrm{ZrN}$, $\left.\mathrm{PuN}-36 \mathrm{ZrN},\left(\mathrm{Pu}_{0.5}, \mathrm{Am}_{0.25}, \mathrm{~Np}_{0.25}\right) \mathrm{N}-36 \mathrm{ZrN},\left(\mathrm{Pu}_{0.5}, \mathrm{Am}_{0.5}\right) \mathrm{N}-36 \mathrm{ZrN}\right)$ tested. Figure 1 shows a nitride fuel specimen of one of the non-fertile, actinide compositions that will be tested in AFC-1. Duplicate fuel specimens of each composition will be irradiated to provide directly comparable PIE samples at two burnup levels (i.e., 5-7 at $\%$ and 20 at $\%$ ) and quality assurance of the data. The fuel specimens are encapsulated in rodlet assemblies.

The rodlet assembly is designed as a miniature fast reactor fuel rod with a standard diameter and reduced length. The rodlet assembly consists of the metallic or nitride fuel column, sodium bond, stainless steel Type 421 (HT-9) cladding and an inert gas plenum. A stainless steel capsule assembly will contain a vertical stack of six rodlet assemblies. The capsule and rodlet radial dimensions of the metallic and nitride fuel specimens are shown in Figure 2. The annular gap between the fuel column and rodlet inner diameter is initially filled by the sodium bond and is designed to accommodate fuel swelling during irradiation. The annular helium-filled gap between the rodlet outer diameter and capsule inner diameter is designed to provide the thermal resistance necessary to achieve the design irradiation temperature of the fuel specimen.

Figure 3 shows the fuel rodlet assembly axial dimensions for the metallic and nitride fuels. The design length of the metallic fuel column is 1.5 -in. with the exception of the $\mathrm{Pu}-60 \mathrm{Zr}$ fuel composition which is 1.0-in.; the metallic fuel column may consist of a maximum of two pins, and the design diameter is 0.158 -in. The design length of the nitride fuel column is 2.0 -in. (consisting of seven to ten pellets) and design diameter is 0.168 -in. The sodium bond is designed to exceed the fuel column length by 0.50 -in. in length. The cladding for all rodlets is 6.0-in. in length (including welded endplugs) with 0.230 -in. outer diameter and 0.194-in. inner diameter.

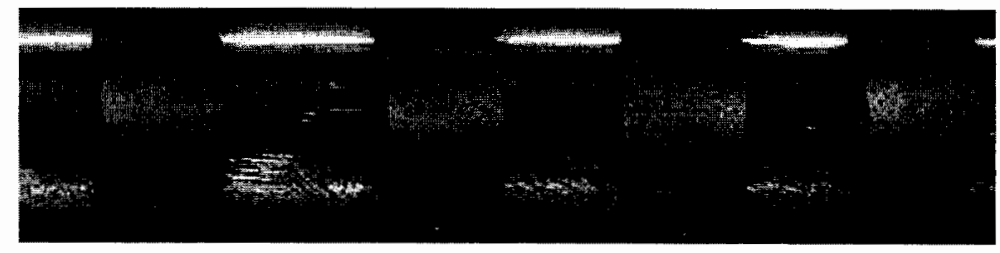

Figure 1. AFC-1 non-fertile, minor actinide bearing nitride pellets $\left(\mathrm{Pu}_{0.8} \mathrm{Am}_{0.2}\right) \mathrm{N}-\mathrm{ZrN}$. 


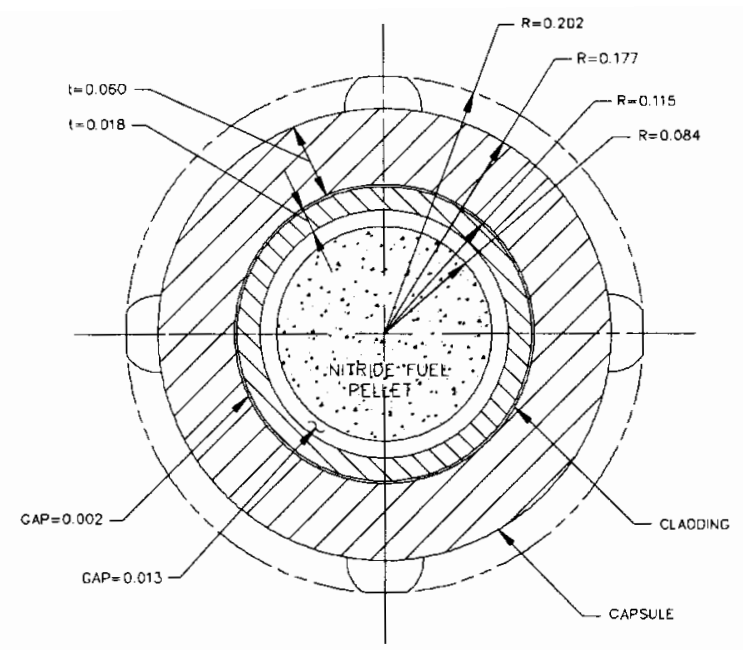

Figure 2. Radial dimensions of capsule and fuel rodlet assemblies for nitride fuel rodlet.

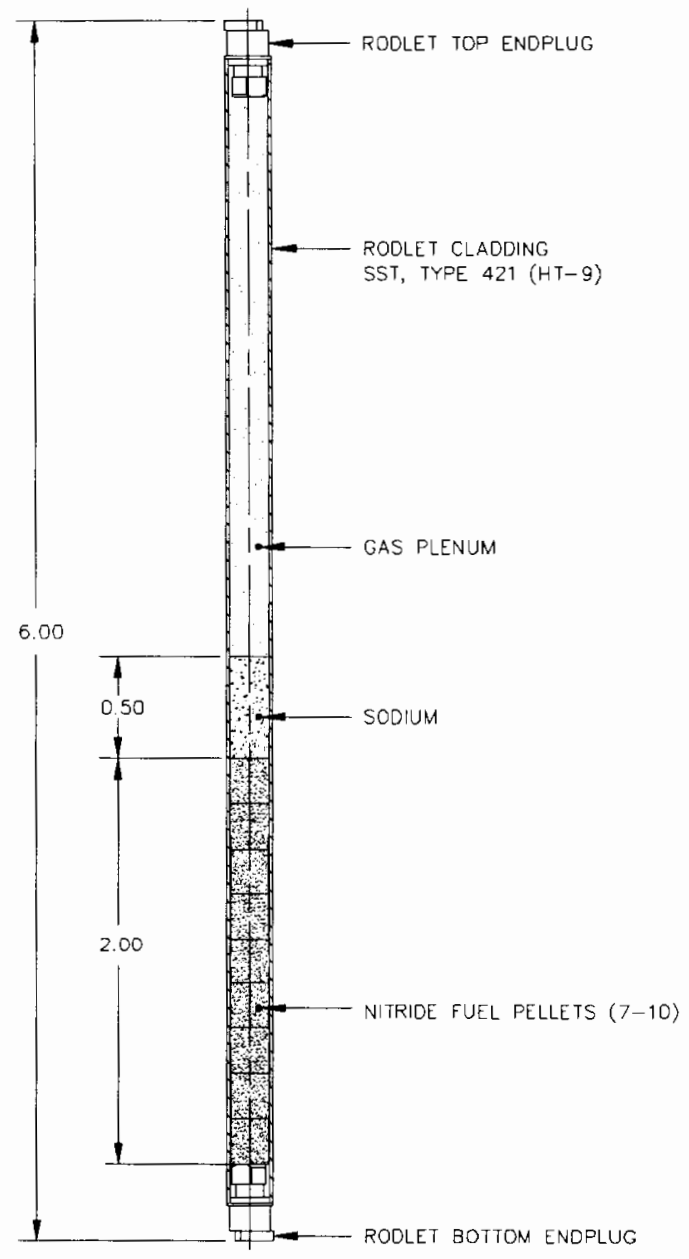

Figure 3. Rodlet assembly axial dimensions for nitride fuel pin. 


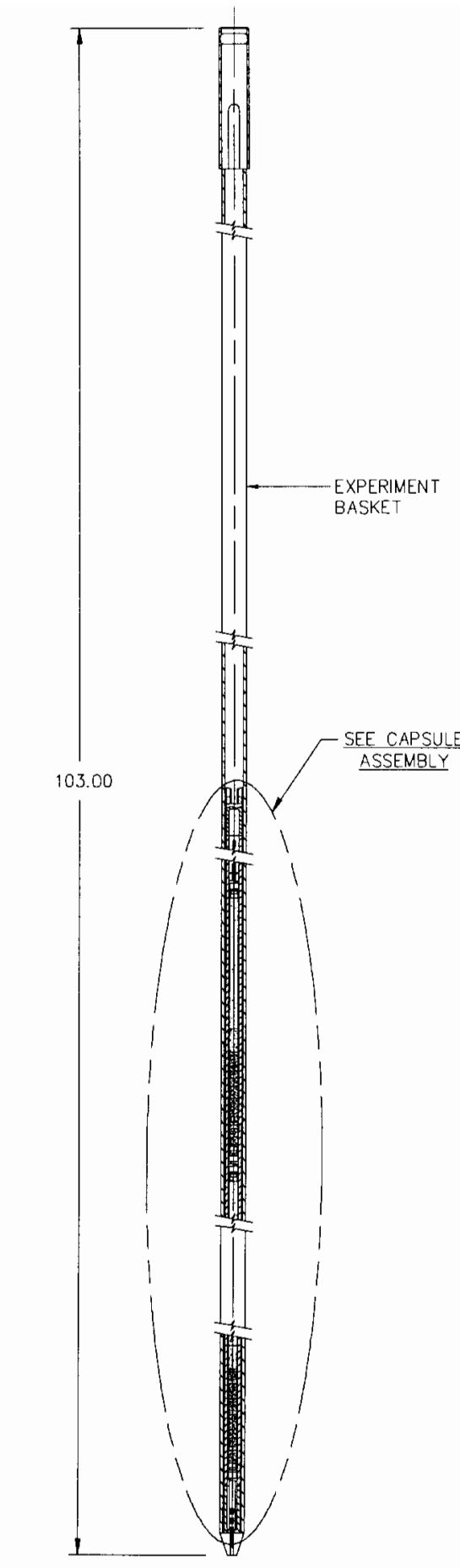

IRRADIATION TEST ASSEMBLY

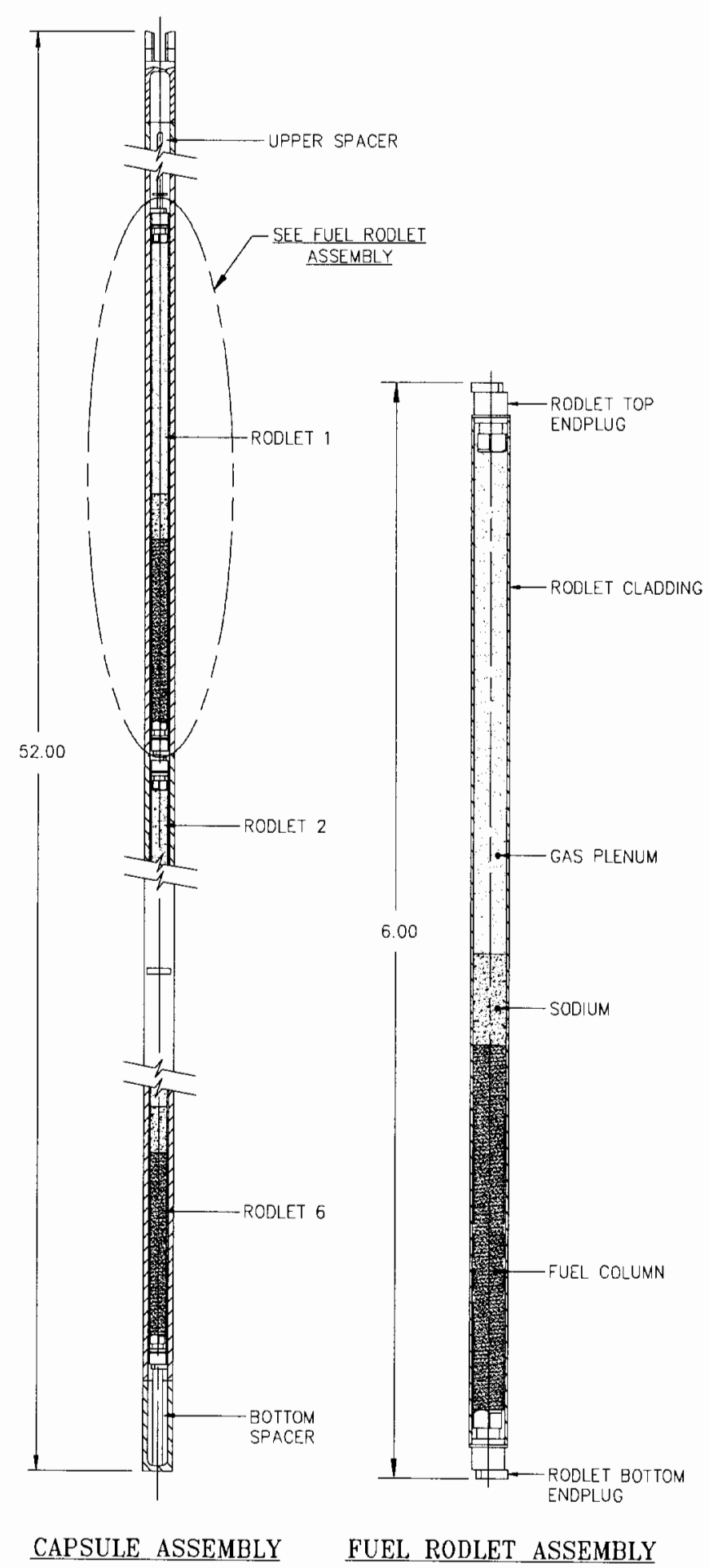

CAPSULE ASSEMBLY FUEL RODLET ASSEMBLY

Figure 4 AFC-1 irradiation test, capsule and rodlet assemblies. 
The purpose of this work was to provide an assessment of the available nitride fuel property database as applied to the AFC-1 fuel test geometry. This report provides a summary of the available uranium nitride fuel properties in detail and provides the fuel property correlations for other nitride fuel systems in Appendix B. The goal of this work was to provide a recommendation to the AFCI FDWG as to the priority of fuel property research and measurements needed to provide an adequate analysis capability in fuel performance calculation.

This work encompassed the following tasks: (1) gather the literature available nitride fuel properties into a referenced database. (2) Provide the fuel property correlations for analytical use. (3) Build a 3-D finite element mesh model of the AFC-1 test fuel geometry. (4) Input the uranium nitride fuel property correlations into the finite element analysis software, ABAQUS. (5) Exercise the model to determine which material properties are most important in predicting the nitride fuel behavior.

The failure mechanisms for nuclear fuel can be varied and interdependent. The material properties, reactor service conditions, and fuel performance characteristics can all affect the fuel behavior. Table 1 presents a list of possible failure mechanisms for in-service nuclear fuel, the driving reactor service condition that may affect the failure, and the fuel design and performance parameter that may play an important role in the contribution to or resistance to failure of the fuel system. For example fission products may corrosively attack fuel components. This interaction and possible corrosion may be hindered or enhanced by temperature, burnup, and time at temperature. Fuel properties such as gap thermoconductivity, FP tranport behavior, microstructure, etc. may play a great importance in the susceptibility of or resistance to FP attack of the fuel system. This table by no means represents an exhaustive summary of the possible fuel failure mechanisms but provides an example of the possibilities.

This report provides the results of a literature survey of the available applicable material properties. To provide a start at accurately modeling of the nitride fuel system this effort has focused on the uranium nitride fuel system. Ultimately, the AFCI fuel development program will move to modeling of the transuranic nitride fuel systems and the properties associated with these systems will be needed. The material properties of the HT -9 are presented as they relate to its use as cladding. Sodium is assumed to be the bonding material and as its properties are well know, standard values are assumed. Finally, details of building a three dimensional solid body model of the fuel pin geometry and the creation of a finite element mesh from the model is presented. Finally, the results of exercising the model are presented, including a comparison of the model using $\mathrm{UO}_{2}$ properties to the results obtained by Stan et al., 2005 in an independent effort at the Los Alamos National Laboratory. 
Table 1. Summary of postulated Nitride Fuel failure mechanisms.

\begin{tabular}{|c|c|c|}
\hline Failure Mechanism & Reactor Service Conditions & Design and Performance Parameters \\
\hline Pressure Vessel Failure & $\begin{array}{l}\text { Temperature } \\
\text { Burnup } \\
\text { Fluence }\end{array}$ & $\begin{array}{l}\text { Clad creep } \\
\text { Fuel clad compatibility } \\
\text { Fission gas release } \\
\text { Swelling and pellet clad interactions }\end{array}$ \\
\hline Irradiation induced failure & $\begin{array}{l}\text { Fluence } \\
\text { Temperature }\end{array}$ & Nitrogen dissolution \\
\hline Fission Product attack & $\begin{array}{l}\text { Temperature } \\
\text { Burnup } \\
\text { Temperature gradient } \\
\text { Time at Temperature }\end{array}$ & $\begin{array}{l}\text { Gap thermoconductivity } \\
\text { Fission product transport behavior } \\
\text { Chemical state and transport behavior } \\
\text { Matrix microstructure }\end{array}$ \\
\hline Fuel migration & $\begin{array}{l}\text { Cycling } \\
\text { Service limits }\end{array}$ & $\begin{array}{l}\text { Fuel chemistry } \\
\text { Impurities }\end{array}$ \\
\hline \multicolumn{3}{|l|}{ Clad/UN/FP compatibility } \\
\hline \multicolumn{3}{|l|}{ Burnup to $>10 \%$} \\
\hline Swelling & $\begin{array}{l}\text { Temperature } \\
\text { Clad design }\end{array}$ & \\
\hline
\end{tabular}




\section{URANIUM NITRIDE FUEL PROPERTIES}

This section is separated into four general sections. Physical properties, mechanical properties, thermal properties, and performance properties. References for each property is provided in the section of applicability to provide for ease of cross-referencing for the reader. Where applicable additional references are provided when a correlation has been developed by a researcher by using data generated in separate studies such that the reader of this report can easily identify the source of the original data used in the property relationship.

\begin{tabular}{ll} 
Physical Properties & Mechanical Properties \\
\hline Lattice Parameter & Creep \\
Critical Temperature & Hardness \\
Density & Modulus of Elasticity \\
Melting Point & $\begin{array}{l}\text { Poisson's Radio } \\
\text { Vapor Pressure }\end{array}$ \\
Bulk Modulus & Modulus of Rigidity \\
Performance Properties & \\
Fission Gas Release & \\
Restrained Swelling & \\
Unrestrained Swelling &
\end{tabular}

\author{
Thermal Properties \\ Diffusion Coefficient \\ Electrical Resistivity \\ Enthalpy \\ Gibb's Free Energy \\ Heat Capacity \\ Specific Heat \\ Heat of Formation \\ Heat of Fusion \\ Heat of Sublimation \\ Heat of Vaporization \\ Thermal Conductivity \\ Thermal Emissivity \\ Thermal Expansion
}

\subsection{Physical Properties}

\subsubsection{Crystal Structure}

Face Centered Cubic

Hayes, S. L., J. K. Thomas and K. L. Peddicord, J. Nucl. Mater., 171, 262, 1990.

Ma, B. M., Nuclear Reactor Materials and Applications, Van Rostrand Reinhold Co., New York, 1983

Rundle, R. E., N. C. Baenziger, A. S. Wilson and R. A. McDonald, The Structures of the Carbides, Nitrides and Oxides of Uranium, J. Am. Chem. Soc., 70, 99 (1984)

Bugl, J. and A. A. Bauer, Phase Relations in the System Uranium-Nitrogen, J. Am. Ceram. Soc., 47, 425 (1964)

Endebrock, R. W., E. L. Foster Jr. and D. L. Keller, Preparation and Properties of Cast UN, BMI-1690 (EURAEC-1206) (1964)

Tagawa, H., Phase Relations and Thermodynamic Properties of the Uranium-Nitrogen System, J. Nucl. Mater., 51, 78 (1974)

Reference(s) as cited by above author(s):

Mueller, M. H. and H. W. Knott, Acta. Cryst. 11 (1958) 751 
Rundell, R. E., N. C. Baenzieger, A. S. Wilson and R. A. McDonald, J. Am. Ceram. Soc. 70 (1948) 99

\subsubsection{Lattice Parameter}

$a=4.879+3.264 \times 10^{-5} T+6.889 \times 10^{-9} T^{2}$

where

$$
\begin{array}{lll}
\mathrm{a} & =\text { Lattice parameter }(\AA) \\
\mathrm{T} & =\text { Temperature }(\mathrm{K})
\end{array}
$$

Valid for $298 \leq \mathrm{T} \leq 2523 \mathrm{~K}$.

Hayes, S. L., J. K. Thomas and K. L. Peddicord, J. Nucl. Mater., 171, 262, 1990.

0.4889

Thetford, R. T., and M. Mignanelli, The Chemistry and Physics of Modeling Nitride Fuels for Transmutation, J. Nucl. Mater., 320, 44 (2003)

Reference(s) as cited by author(s):

Matzke, Hj., Science of Advanced LMFBR Fuels, North Holland, Amsterdam, 1986

Billone, M. C., V. Z. Jankus, J. M. Kramer, C. I. Yang, in: J. Leary, H. Kittle (Eds.), Advanced LMFBR Fuels, Topical Meeting Proceedings, Tucson, Arizona, 1997 (ERDA)

Aria, Y., T. Iwai, K. Nakajima, Y. Suzuki, Recent Progress of Nitride Fuel Development in JAERI - Fuel Propertym Irradiation Behavior and Application to Dry Reprocessing, Proceedings of the International Conference, Global '97, Yokohama, Japan, 5-10 October 1997, Vol. 1, p. 664

Nakajima, K., Y. Arai, Y. Suzuki, J. Nucl. Mater. 247 (1997) 33

Cocuaud, N., R. J. M. Konings, A. Conti, E. Picard, Hj. Matzke, Inert Matrices, U-Free Pu Fuels and Am Targets - Synthesis of CAPRA, SPIN and EFTTRA studies, CES Note Technique LPCA No. 61, March 1998

Charvillat, J. P., U. Benedict, D. Damien, C. H. de Novion, A. Wojakowski, W. Müller, R. Linder (Eds.), Transplutonium Elements, North Holland, Amsterdam, 1976

$$
4.889 \pm 0.001 \AA
$$

Bugl, J., and A. A. Bauer, Phase Relations in the System Uranium-Nitrogen, J. Am. Ceram. Soc., 47,425 (1964)

$$
4.8895 \pm 0.0005 \AA
$$

Tagawa, H., Phase Relations and Thermodynamic Properties of the Uranium-Nitrogen System, J. Nucl. Mater., 51, 78 (1974)

Reference(s) as cited by author(s): 
Anselin, F., J. Nucl. Mater. 10 (1963) 301

Austin, A. E. and A. F. Gerds, Battelle (USA) Report, BMI-1272 (1958)

Benz, R. and W. B. Hutchinson, J. Nucl. Mater. 36 (1970) 135

Berthold, H. J. and C. Delliehausen, Angew. Chem. 78 (1966) 750

Evans, P. E. and T. J. Davies, J. Nucl. Mater. 10 (1963) 43

Kempter, C. P. and R. B. Holden, Compounds of Interest in Nuclear Reactor Technology, ed. J. T. Waber, P. Chiotti and W. N. Miner (Edwards Bors. Inc., Ann Arbor, Mich., 1964) p. 225

Mueller, M. H. and H. W. Knott, Acta. Cryst. 11 (1958) 751

Rundell, R. E., N. C. Baenzieger, A. S. Wilson and R. A. McDonald, J. Am. Ceram. Soc. 70 (1948) 99

Sasa, Y. and T. Atoda, J. Am. Ceram. Soc. 53 (1970) 102

Tagawa, H. and N. Masaki, J. Inorg Nucl. Chem., in press.

Tenery, V. J. and E. S. Bomar, J. Am. Ceram. Soc. 54 (1971) 274

Venard, J. T., J. E. Spruiell and O. B. Cavin, J. Nucl. Mater. 24 (1967) 245

Williams, J. and R. A. Sambell, J. Less-Common Metals 1 (1959) 217

\subsubsection{Critical Temperature}

$10620 \mathrm{~K} \quad$ for $\mathrm{UN}_{1.00}$ (estimated)

Johnson, C. E., Thermophysical and Mechanical Properties of Advanced Carbide and Nitride Fuels, ANL-AFP-27, June 1976

\subsubsection{Density}

$\rho=14.42-2.997 \times 10^{-4} T-4.897 \times 10^{-8} T^{2}$

where

$$
\begin{aligned}
\rho & =\text { Density }\left(\frac{g}{\mathrm{~cm}^{3}}\right) \\
\mathrm{T} & =\text { Temperature }(\mathrm{K}) .
\end{aligned}
$$

Valid for $298 \leq \mathrm{T} \leq 2523 \mathrm{~K}$

Hayes, S. L., J. K. Thomas and K. L. Peddicord, J. Nucl. Mater., 171, 262, 1990.

$14.330 \mathrm{~g} / \mathrm{cc} \quad \mathrm{U} 14 \mathrm{~N}$ (Theoretical) 


\section{$14.380 \mathrm{~g} / \mathrm{cc} \quad \mathrm{U} 15 \mathrm{~N} \quad$ (Theoretical)}

Thetford, R. T. and M. Mignanelli, The Chemistry and Physics of Modeling Nitride Fuels for Transmutation, J. Nucl. Mater., 320, 44 (2003)

Reference(s) as cited by author(s):

Matzke, Hj., Science of Advanced LMFBR Fuels, North Holland, Amsterdam, 1986

Billone, M. C., V. Z. Jankus, J. M. Kramer, C. I. Yang, in: J. Leary, H. Kittle (Eds.), Advanced LMFBR Fuels, Topical Meeting Proceedings, Tucson, Arizona, 1997 (ERDA)

Aria, Y., T. Iwai, K. Nakajima, Y. Suzuki, Recent Progress of Nitride Fuel Development in JAERI Fuel Propertym Irradiation Behavior and Application to Dry Reprocessing, Proceedings of the International Conference, Global '97, Yokohama, Japan, 5-10 October 1997, Vol. 1, p. 664

Nakajima, K., Y. Arai, Y. Suzuki, J. Nucl. Mater. 247 (1997) 33

Cocuaud, N., R. J. M. Konings, A. Conti, E. Picard, Hj. Matzke, Inert Matrices, U-Free Pu Fuels and Am Targets - Synthesis of CAPRA, SPIN and EFTTRA studies, CES Note Technique LPCA No. 61, March 1998.

Charvillat, J. P., U. Benedict, D. Damien, C. H. de Novion, A. Wojakowski, W. Müller, R. Linder (Eds.), Transplutonium Elements, North Holland, Amsterdam, 1976

$14.32 \mathrm{~g} / \mathrm{cc}$ or $\mathrm{g} / \mathrm{cm}^{3}$

Rundle, R. E., N. C. Baenziger, A. S. Wilson and R. A. McDonald, The Structures of the Carbides, Nitrides and Oxides of Uranium, J. Am. Chem. Soc., 70, 99 (1984)

Bugl, J. and A. A. Bauer, Phase Relations in the System Uranium-Nitrogen, J. Am. Ceram. Soc., 47, 425 (1964)

Endebrock, R. W., E. L. Foster Jr. and D. L. Keller, Preparation and Properties of Cast UN, BMI-1690 (EURAEC-1206) (1964)

Ma, B. M., Nuclear Reactor Materials and Applications, Van Rostrand Reinhold Co., New York, 1983

\subsubsection{Melting Point}
Average Melting Point: $2860^{\circ} \mathrm{C}$
Under 4 atm of $\mathrm{N}_{2}$ pressure

DeCrescente, M. A., M. S. Freed and S. D. Caplow, PWAC-488, "Uranium Nitride Fuel Development," Pratt and Whitney Aircraft-CANEL Oct. 12, 1963

$2650^{\circ} \mathrm{C}$

Ma, B. M., Nuclear Reactor Materials and Applications, Van Rostrand Reinhold Co., New York, 1983

$T_{m}=3035.0 P_{N_{2}}^{0.02832}$ 
where

$$
\begin{aligned}
& \mathrm{Tm}=\quad \text { Melting Point of } \mathrm{UN}(\mathrm{K}) \\
& P_{N_{2}}=\mathrm{N}
\end{aligned}
$$

Valid for $1 \times 10^{-13} \leq \mathrm{P} \leq 7.5 \mathrm{~atm}$

Includes all conditions of $\mathrm{N}$ partial pressures foreseeable in nuclear fuel modeling.

Hayes, S. L., J. K. Thomas and K. L. Peddicord, J. Nucl. Mater., 171, 300, 1990.

$$
2850 \pm 30^{\circ} \mathrm{C} \quad \text { with } \mathrm{N}_{2} \text { pressure } \geq 2.5 \mathrm{~atm}
$$

Bugl, J. and A. A. Bauer, Phase Relations in the System Uranium-Nitrogen, J. Am. Ceram. Soc., 47, 425 (1964)

Olson, W. M. and R. N. R. Mulford, The Decomposition and Melting Point of Uranium Mononitride, J. Phys. Chem., 67, 952 (1963)

Endebrock, R. W., E. L. Foster Jr. and D. L. Keller, Preparation and Properties of Cast UN, BMI-1690 (EURAEC-1206) (1964)

$3103 \pm 30 \mathrm{~K} \quad \mathrm{~N}_{2}$ pressure of $3.5 \mathrm{~atm}$

$3123 \mathrm{~K} \quad \mathrm{~N}_{2}$ pressure of $2.5 \mathrm{~atm}$

Tagawa, H., "Phase Relations and Thermodynamic Properties of the Uranium-Nitride System," Journal of Nuclear Materials, Vol. 51, 1974, p. 78-89

\subsubsection{Vapor Pressure}

$\log _{10}\left(P_{N_{2}}\right)=4.492-\left(\frac{2.91 \cdot 10^{4}}{T}\right)$

where

$$
\begin{aligned}
& \mathrm{P}=\quad \text { Vapor Pressure (N2 over UN) (atm) } \\
& \mathrm{T}=\quad \text { Temperature }(\mathrm{K}) \\
& \text { Valid for } 1908 \leq \mathrm{T} \leq 2266 \mathrm{~K} \\
& \text { Composition: } \quad \begin{array}{l}
1500 \mathrm{ppm} \mathrm{C} \\
500-2000 \mathrm{ppm} \mathrm{O}
\end{array}
\end{aligned}
$$

Table 2 is compiled using the above equation and is shown graphically in Figure 5. 
Table 2. Vapor Pressure of $\mathrm{N}_{2}$ over UN.

\begin{tabular}{|c|c|}
\hline $\begin{array}{c}\text { Temperature } \\
(\mathrm{K})\end{array}$ & $\begin{array}{c}\text { Pressure } \\
(\mathrm{atm})\end{array}$ \\
\hline 1910 & $1.80467 \mathrm{E}-11$ \\
\hline 1925 & $2.37201 \mathrm{E}-11$ \\
\hline 1950 & $3.70615 \mathrm{E}-11$ \\
\hline 1975 & $5.72562 \mathrm{E}-11$ \\
\hline 2000 & $8.74984 \mathrm{E}-11$ \\
\hline 2025 & $1.32321 \mathrm{E}-10$ \\
\hline 2050 & $1.98097 \mathrm{E}-10$ \\
\hline 2075 & $2.937 \mathrm{E}-10$ \\
\hline 2100 & $4.31377 \mathrm{E}-10$ \\
\hline 2125 & $6.27888 \mathrm{E}-10$ \\
\hline 2150 & $9.05975 \mathrm{E}-10$ \\
\hline 2175 & $1.29625 \mathrm{E}-09$ \\
\hline 2200 & $1.83962 \mathrm{E}-09$ \\
\hline 2225 & $2.59029 \mathrm{E}-09$ \\
\hline 2250 & $3.61965 \mathrm{E}-09$ \\
\hline & \\
\hline & \\
\hline
\end{tabular}

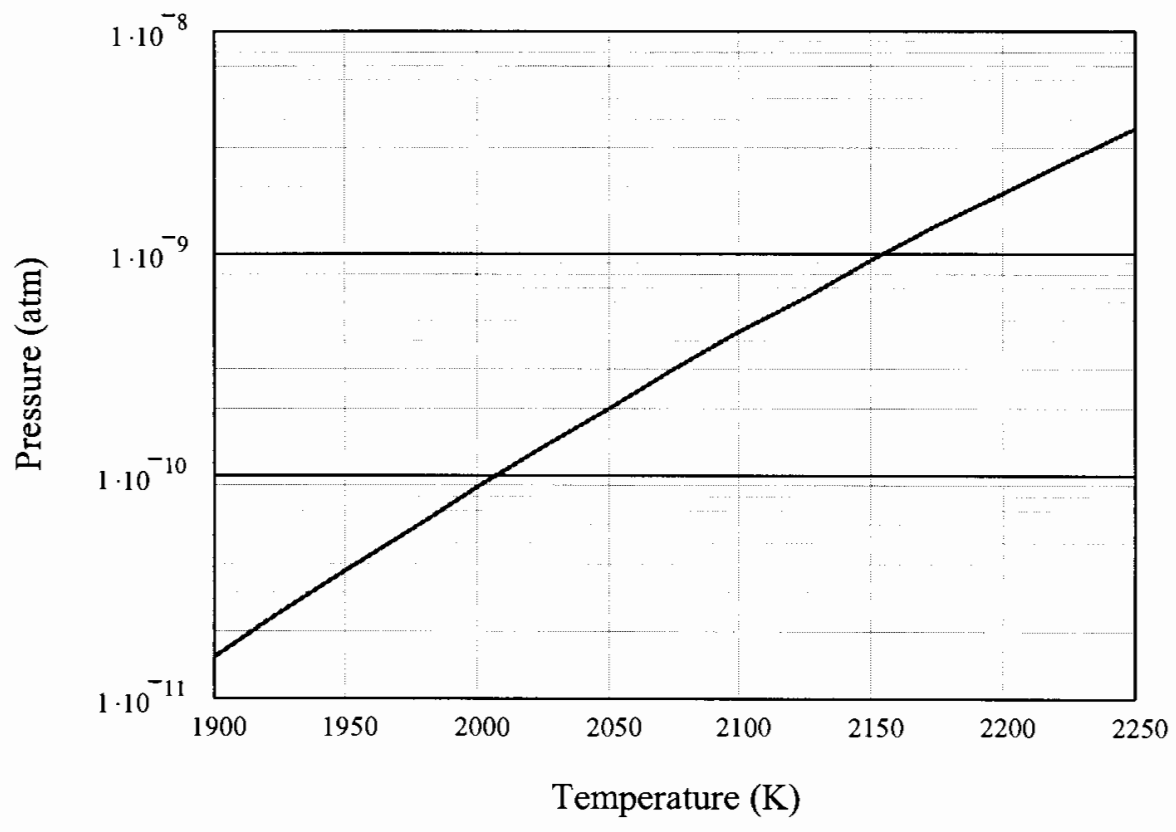

Figure 5. Vapor pressure of $\mathrm{N}_{2}$ over UN. 
DeCrescente, M. A., M. S. Freed and S. D. Caplow, PWAC-488, "Uranium Nitride Fuel Development," Pratt and Whitney Aircraft-CANEL Oct. 12, 1963

Reference(s) as cited by author(s):

BMI-X-10083, D. L. Keller, "Development of Uranium Mononitride," Quarterly Progress Report for January-March, 1964 (Preliminary), Battelle Memorial Institute.

Olson, W. M. and R. N. R. Mulford, "The Decomposition Pressure and Melting Point of UN," private communication

BMI-X-10083, D. L. Keller, “Development of Uranium Mononitride,” Quarterly Progress Report for October-December, 1963 (Preliminary), Battelle Memorial Institute.

Rauh, E. G. and R. J. Thorne. J. Chem. Phys. 22, 141 (1954).

$\log _{10}\left(P_{N_{2}}\right)=1.8216+1.882 \times 10^{-3} T-\frac{23545.4}{T}$

Valid for $1400 \leq \mathrm{T} \leq 3170 \mathrm{~K}$

$\log _{10}\left(P_{U}\right)=6.9654-5.137 \times 10^{-4} T-\frac{26616.1}{T}$

Valid for $1400 \leq \mathrm{T} \leq 2400 \mathrm{~K}$

where

$\mathrm{P} \quad=\quad$ Vapor Pressure over UN (atm)

$\mathrm{T}=$ Temperature $(\mathrm{K})$

Total pressure

$P_{T}=P_{N_{2}}+P_{U}$

Stable, could be used to produce reasonable estimates at higher temperatures.

Hayes, S. L., J. K. Thomas and K. L. Peddicord, J. Nucl. Mater., 171, 300, 1990.

$$
\begin{aligned}
& \log \left(P_{U}\right)=5.805-\frac{26010}{T} \\
& \log \left(P_{N_{2}}\right)=9.849-\frac{31980}{T}
\end{aligned}
$$

where

$$
\mathrm{P} \quad=\quad \text { Pressure }(\mathrm{atm})
$$




$$
\mathrm{T} \quad=\quad \text { Temperature }(\mathrm{K}) \text {. }
$$

Tagawa, H., Phase Relations and Thermodynamic Properties of the Uranium-Nitrogen System, J. Nucl. Mater., 51, 78 (1974)

$$
\begin{aligned}
& \log \left(P_{U}\right)=(5.825 \pm 0.871)-\frac{26854 \pm 1793}{T} \\
& \log \left(P_{N_{2}}\right)=(8.904 \pm 0.8)-\frac{30464 \pm 1647}{T}
\end{aligned}
$$

where

$$
\begin{array}{lll}
\mathrm{P} & = & \text { Pressure }(\mathrm{atm}) \\
\mathrm{T} & =\text { Temperature }(\mathrm{K})
\end{array}
$$

Gingerich, K. A., Vaporization of Uranium Mononitride and Heat of Sublimation of Uranium, J. Chem. Phys., 51, 4433 (1969)

\subsection{Mechanical Properties}

\subsubsection{Creep}

$$
\dot{\varepsilon}=2.75 \times 10^{5} e^{\left(\frac{-6200}{8.31451 T}\right)}
$$

Valid for $1100 \leq \mathrm{T} \leq 1250 \mathrm{~K}$ at a stress of $6000 \mathrm{psi}$

$$
\dot{\varepsilon}=6.9 \times 10^{5} e^{\left(\frac{-60800}{8.31451 T}\right)}
$$

Valid for $1100 \leq \mathrm{T} \leq 1350 \mathrm{~K}$ at a stress of $8000 \mathrm{psi}$

$\dot{\varepsilon}=$ Steady-State Creep Rate $(\mathrm{in} / \mathrm{in} \cdot \mathrm{hr})$

where

$$
\mathrm{T}=\text { Temperature }(\mathrm{K}) \text {. }
$$

Density: $13.35-13.60(g / c c)$

Composition: $\quad 5.25 \mathrm{w} / \mathrm{o} \mathrm{N} 2$ $1100 \mathrm{ppm} \mathrm{C}$ $2600 \mathrm{ppm} \mathrm{O}$

DeCrescente, M. A., M. S. Freed and S. D. Caplow, PWAC-488, "Uranium Nitride Fuel Development," Pratt and Whitney Aircraft-CANEL Oct. 12, 1963. 
Reference(s) as cited by author(s):

PWAC-482, M. H. Fassler, F. J. Hugel and M. A. DeCrescente, "The Compressive Creep of UC and UN," September 30, 1965, Pratt and Whitney Aircraft-CANEL.

Fassler, M. H., F. J. Huegel and M. A. DeCrescemte, Compressive Creep of UC and UN, PWAC-428, Part I (1965)

$\dot{\varepsilon}=2.054 \times 10^{-3} \sigma^{4.5} e^{\left(\frac{-39369.5}{T}\right)}$

where

$\dot{\varepsilon}=$ Steady-State Creep Rate (s-1)

$\sigma \quad=\quad$ Stress $(\mathrm{MPa})$

$\mathrm{T}=$ Temperature $(\mathrm{K})$

Independent of grain size

Correlation should produce reasonable estimates at lower temperatures

Creep Rate Porosity Correction

$f(P)=\frac{0.987}{(1-P)^{27.6}} e^{-8.65 P}$

where
$f(P)=$ Factor by which $\dot{\varepsilon}$ is multiplied to get a prediction of UN at porosity $\mathrm{P}$
$\mathrm{P} \quad=$ Porosity (volume fraction)

Hayes, S. L., J. K. Thomas and K. L. Peddicord, J. Nucl. Mater., 171, 271, 1990.

\subsubsection{Hardness}

Polynomial Regression of the data produces

$$
H D=951.8(1-2.1 P) e^{-1.88 \times 10^{-3} T}
$$

where

$$
\begin{array}{ll}
\mathrm{HD} & =\text { Diamond Point Hardness }\left(\mathrm{kg} / \mathrm{mm}^{2}\right) \\
\mathrm{P} & =\text { Porosity (volume fraction) } \\
\mathrm{T} & =\text { Temperature }(\mathrm{K})
\end{array}
$$


Valid for $0 \leq \mathrm{P} \leq 0.26$ and $298 \leq \mathrm{T} \leq 1673 \mathrm{~K}$

Caution should be used if porosity is above $26 \%$.

Should not be used below $298 \mathrm{~K}$.

Stable at high temperatures, could be used to give reasonable estimates of hardness above $1673 \mathrm{~K}$.

Hayes, S. L., J. K. Thomas and K. L. Peddicord, J. Nucl. Mater., 171, 271, 1990.

\subsubsection{Hot Hardness}

Polynomial Regression of the data produces

$$
H H D=-4 \times 10^{-9} T^{4}+2 \times 10^{-5} T^{3}-0.0289 T^{2}-21.484 T-5724.7
$$

where

HHD $=$ hardness (Diamond Point)

$\mathrm{T}=$ Temperature $\left({ }^{\circ} \mathrm{C}\right)$

With a correlation coefficient of $\mathrm{R}^{2}=1$.

DeCrescente, M. A., M. S. Freed and S. D. Caplow, PWAC-488, "Uranium Nitride Fuel Development," Pratt and Whitney Aircraft-CANEL Oct. 12, 1963.

Reference(s) as cited by author(s):

PWAC-1003, “Advanced Materials Program of June, 1962,” Pratt and Whitney Aircraft-CANEL.

BMI-X-10083, D. L. Keller, "Development of Uranium Mononitride," Quarterly Progress Report for July-September, 1961 (Preliminary), Battelle Memorial Institute.

Speidel, E. O. and D. L. Keller, Fabrication and Properties of Hot-Pressed Uranium Mononitride, BMI-1633 (1963)

Endebrock, R. W., E. L. Foster Jr. and D. L. Keller, Preparation and Properties of Cast UN, BMI-1690 (EURAEC-1206) (1964)

Harrison, J. D. L., Fuels and Materials Development Program Quarterly Progress Report for Period Ending June 30, 1968, ORNL-4330 (1968) 


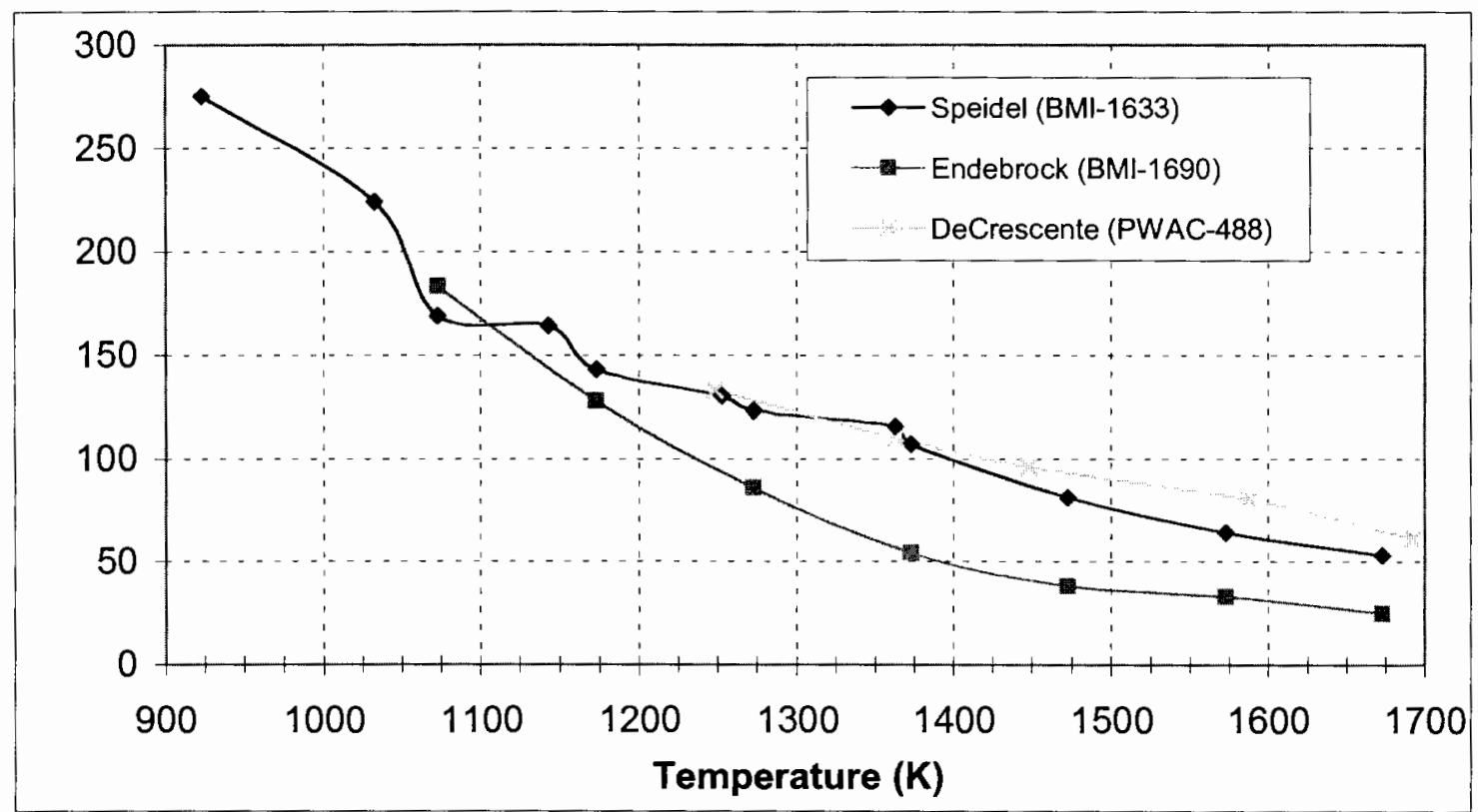

Figure 6. Hardness as a function of temperature.

\subsubsection{Modulus of Elasticity (Young's Modulus)}

$E=0.258 D^{3.0002}\left[1-2.375 \times 10^{-5} T\right]$

where

$\mathrm{E}=$ Modulus of Elasticity for porous UN $(\mathrm{MPa})$

$\mathrm{D}=$ Percent Theoretical Density of Fuel (\%)

$\mathrm{T}=$ Temperature $(\mathrm{K})$.

Valid for $70 \leq \mathrm{D} \leq 100 \%$ and $298 \leq \mathrm{T} \leq 1473 \mathrm{~K}$.

Hayes, S. L., J. K. Thomas and K. L. Peddicord, J. Nucl. Mater., 171, 271, 1990.

$4.65 \times 105-5.35 \times 105 \mathrm{~kg} / \mathrm{cm}^{2}$

$4.30 \times 105 \mathrm{~kg} / \mathrm{cm} 2 \quad$ for $(\mathrm{U} 0.85, \mathrm{Pu} 0.15) \mathrm{N}$

Ma, B. M., Nuclear Reactor Materials and Applications, Van Rostrand Reinhold Co., New York, 1983 $38.45 \times 10^{6} \mathrm{psi} \quad$ at $298 \mathrm{~K}$

Guinan, M. and C. F. Cline, Elastic Properties of Uranium Mononitride at 298 K, J. Nucl. Mater., 43, 205 (1972)
$2.19092 \times 10^{6} \mathrm{~atm}$
For $92.8 \%$ dense 

$2.24026 \times 10^{6} \mathrm{~atm}$
For $95.0 \%$ dense
$2.47712 \times 10^{6} \mathrm{~atm}$
For $97.0 \%$ dense
$2.50673 \times 10^{6} \mathrm{~atm}$
For $98.5 \%$ dense
$2.58568 \times 10^{6} \mathrm{~atm}$
For theoretical dense

Whaley, H. L., W. Fulkerson and R. A. Potter, Elastic Moduli and Debye Temperature of Polycrystalline Urnaium Nitride by Ultasonic Velocity Measurements, J. Nucl. Mater., 31, 345 (1969)

$E=(100-227 P)\left(2.69-2.56 \times 10^{-4} T\right)$

where
$\mathrm{E}=$ Modulus of Elasticity $(\mathrm{GPa})$
$\mathrm{P} \quad=\quad$ Porosity (Volume Fraction)
$\mathrm{T}=$ Temperature $(\mathrm{K})$.

Johnson, C. E., Thermophysical and Mechanical Properties of Advanced Carbide and Nitride Fuels, ANL-AFP-27, June 1976

\subsubsection{Poisson's Ratio}

$v=1.26 \times 10^{-3} D^{1.174}$

where
$\mathrm{v} \quad=\quad$ Poisson's Ratio
$\mathrm{D}=$ Percent Theoretical Density of Fuel $(\%)$

Valid for $70 \leq \mathrm{D} \leq 100 \%$

Produces physical predictions for all values of porosity

Can be used for estimations for Poisson's Ratio of UN for porosities above $30 \%$

Hayes, S. L., J. K. Thomas and K. L. Peddicord, J. Nucl. Mater., 171, 271, 1990.

$$
\begin{aligned}
& 0.26-0.28 \\
& 0.275 \quad \text { for }(\mathrm{U} 0.85, \mathrm{Pu} 0.15) \mathrm{N}
\end{aligned}
$$

Ma, B. M., Nuclear Reactor Materials and Applications, Van Rostrand Reinhold Co., New York, 1983 0.272 
Guinan, M. and C. F. Cline, Elastic Properties of Uranium Mononitride at 298 K, J. Nucl. Mater., 43, $205(1972)$

0.26 For $92.8 \%$ and $95.0 \%$ dense

$0.27 \quad$ For $97.0 \%$ and $98.5 \%$ dense

0.263 For theoretical dense

Whaley, H. L., W. Fulkerson and R. A. Potter, Elastic Moduli and Debye Temperature of Polycrystalline Urnaium Nitride by Ultasonic Velocity Measurements, J. Nucl. Mater., 31, 345 (1969)

$0.263 \quad$ at $298 \mathrm{~K}$

Johnson, C. E., Thermophysical and Mechanical Properties of Advanced Carbide and Nitride Fuels, ANL-AFP-27, June 1976

\subsubsection{Modulus of Rigidity (Shear Modulus)}

$G=1.44 \times 10^{-2} D^{3.446}\left[1-2.375 \times 10^{-5} T\right]$

where

$\mathrm{G}=$ Modulus of Rigidity $(\mathrm{MPa})$

$\mathrm{D}=$ Percent Theoretical Density of Fuel (\%)

$\mathrm{T}=$ Temperature $(\mathrm{K})$

Valid for $70 \leq \mathrm{D} \leq 100 \%$ and $298 \leq \mathrm{T} \leq 1473 \mathrm{~K}$ porosity.

Behavior of non-linear form of porosity dependence produces physical predictions for all values of

Caution should be used if correlation is used above $1473 \mathrm{~K}$.

Hayes, S. L., J. K. Thomas and K. L. Peddicord, J. Nucl. Mater., 171, 271, 1990.

$2.20 \times 105-2.40 \times 105 \mathrm{~kg} / \mathrm{cm}^{2}$

$2.10 \times 10^{5} \mathrm{~kg} / \mathrm{cm}^{2} \quad$ for $\left(\mathrm{U}_{0.85}, \mathrm{Pu}_{0.15}\right) \mathrm{N}$

Ma, B. M., Nuclear Reactor Materials and Applications, Van Rostrand Reinhold Co., New York, 1983

$15.13 \times 10^{6} \mathrm{psi} \quad$ at $298 \mathrm{~K}$

Guinan, M. and C. F. Cline, Elastic Properties of Uranium Mononitride at 298 K, J. Nucl. Mater., 43, 205 (1972) 

$868.472 \times 10^{3} \mathrm{~atm}$
For $92.8 \%$ dense
$888.21 \times 10^{3} \mathrm{~atm}$
For $95.0 \%$ dense
$957.293 \times 10^{3} \mathrm{~atm}$
For $97.0 \%$ dense
$967.162 \times 10^{3} \mathrm{~atm}$
For $98.5 \%$ dense
$1.02342 \times 10^{6} \mathrm{~atm}$
For theoretical dense

Whaley, H. L., W. Fulkerson and R. A. Potter, Elastic Moduli and Debye Temperature of Polycrystalline Urnaium Nitride by Ultasonic Velocity Measurements, J. Nucl. Mater., 31, 345 (1969)

\subsubsection{Bulk Modulus}

$$
K=1.33 \times 10^{-3} D^{4.074}\left[1-2.375 \times 10^{-5} T\right]
$$

where

$$
\begin{aligned}
& \mathrm{K}=\text { Bulk Modulus }(\mathrm{MPa}) \\
& \mathrm{D}=\text { Percent Theoretical Density of Fuel }(\%) \\
& \mathrm{T}=\text { Temperature }(\mathrm{K})
\end{aligned}
$$

Valid for $70 \leq \mathrm{D} \leq 100 \%$ and $298 \leq \mathrm{T} \leq 1473 \mathrm{~K}$ porosity.

Behavior of non-linear form of porosity dependence produces physical predictions for all values of

Caution should be used if correlation is used above $1473 \mathrm{~K}$

Hayes, S. L., J. K. Thomas and K. L. Peddicord, J. Nucl. Mater., 171, 271, 1990.
$1.51983 \times 10^{6} \mathrm{~atm}$
For $92.8 \%$ dense
$1.5593 \times 10^{6} \mathrm{~atm}$
For $95.0 \%$ dense
$1.79616 \times 10^{6} \mathrm{~atm}$
For $97.0 \%$ dense
$1.8159 \times 10^{6} \mathrm{~atm}$
For $98.5 \%$ dense
$1.81787 \times 10^{6} \mathrm{~atm}$
For theoretical dense

Whaley, H. L., W. Fulkerson and R. A. Potter, Elastic Moduli and Debye Temperature of Polycrystalline Uranium Nitride by Ultrasonic Velocity Measurements, J. Nucl. Mater., 31, 345 (1969) 


\subsection{Thermal Properties}

\subsubsection{Diffusion Coefficient}

$\mathrm{DN}$ in $\mathrm{UN}=2.2516 \times 10^{-5} P^{0.4134} g^{-0.737+2.179 \times 10^{-4} T} e^{\left(\frac{-19214.7}{T}\right)}$

where

$$
\begin{aligned}
& \mathrm{DN} \text { in UN }=\text { Tracer Diffusion Coefficient of N in UN }\left(\mathrm{cm}^{2} / \mathrm{s}\right) \\
& \mathrm{P}=\text { Partial Pressure of N (atm) } \\
& \mathrm{g}=\text { Grain Size }(\mu \mathrm{m}) \\
& \mathrm{T}=\text { Temperature }(\mathrm{K})
\end{aligned}
$$

Valid for $25 \leq \mathrm{g} \leq 5000 \mu \mathrm{m}, 0.001 \leq \mathrm{P} \leq 2 \mathrm{~atm}$, and $1503 \leq \mathrm{T} \leq 2273 \mathrm{~K}$.

Should include most prototypic fuel and fuel elements conditions.

DU in UN $=2.2146 \times 10^{-11} P^{0.6414} e^{\left(\frac{-7989.3}{T}\right)}$

where

$$
\begin{aligned}
& \text { DU in UN }=\text { Tracer Diffusion Coefficient of U in UN }\left(\mathrm{cm}^{2} / \mathrm{s}\right) \\
& \mathrm{P}=\text { Partial Pressure of } \mathrm{N}(\mathrm{atm}) \\
& \mathrm{T}=\text { Temperature }(\mathrm{K})
\end{aligned}
$$

Valid for $1873 \leq \mathrm{T} \leq 2133 \mathrm{~K}$ and $2.6 \times 10-5 \leq \mathrm{P} \leq 0.66 \mathrm{~atm}$.

Hayes, S. L., J. K. Thomas and K. L. Peddicord, J. Nucl. Mater., 171, 289, 1990.

\subsubsection{Electrical Resistivity}

$\rho=157.1+61.3 \times 10^{-3} T-47.1 \times 10^{-6} T^{2}+23.0 \times 10^{-9} T^{3}$

where

$$
\begin{array}{rll}
\rho & =\text { Electrical Resistivity }(\mu \Omega-\mathrm{cm}) \\
\mathrm{T} & =\text { Temperature }\left({ }^{\circ} \mathrm{C}\right)
\end{array}
$$




\section{Composition: $\quad 5.4 \mathrm{w} / \mathrm{o} \mathrm{N} 2$ \\ $750 \mathrm{ppm} \mathrm{C}$ \\ $1000 \mathrm{ppm} \mathrm{O}$}

DeCrescente, M. A., M. S. Freed and S. D. Caplow, PWAC-488, "Uranium Nitride Fuel Development," Pratt and Whitney Aircraft-CANEL Oct. 12, 1963

Reference(s) as cited by author(s):

PWAC-481, B. A. Hayes and M. A. DeCrescente, "Thermal Conductivity of UN," September 30, 1965, Pratt and Whitney Aircraft-CANEL.

$\rho=71.49 e^{2.14 P} T^{0.125}$

where

$$
\begin{array}{lll}
\rho & = & \text { Electrical Resistivity }(\mu \Omega-\mathrm{cm}) \\
\mathrm{P} & = & \text { Porosity (volume fraction) } \\
\mathrm{T} & = & \text { Fuel Temperature }(\mathrm{K})
\end{array}
$$

Valid for $298 \leq \mathrm{T} \leq 1600 \mathrm{~K}$ and $0 \leq \mathrm{P} \leq 16 \%$.

Hayes, S. L., J. K. Thomas and K. L. Peddicord, J. Nucl. Mater., 171, 289, 1990.

Speidel, E. O. and D. L. Keller, Fabrication and Properties of Hot-Pressed Uranium Mononitride, BMI-1633 (1963)

Moore, J. P., W. Fulkerson and D. L. McElroy, Thermal Conductivity, Electrical Resistivity, and Seebeck Coefficient of Uranium Mononitride, J. Am. Ceram. Soc., 53, 76 (1970)

Endebrock, R. W., E. L. Foster Jr. and D. L. Keller, Preparation and Properties of Cast UN, BMI-1690 (EURAEC-1206) (1964)

Hayes, B. A. and M. A. DeCrescente, Thermal Conductivity and Electrical Resistivity of Uranium Mononitride, PWAC-481 (1965)

\subsubsection{Enthalpy}

$$
H(T)=\frac{51.4 \theta}{e^{\left(\frac{\theta}{T}\right)}-1}+4.746 \times 10^{-3} T^{2}+1.4609 \times 10^{7} e^{\left(\frac{-18081}{T}\right)}
$$

or

$$
H(T)-H(298)=\frac{51.4 \theta}{e^{\left(\frac{\theta}{T}\right)}-1}+4.746 \times 10^{-3} T^{2}-8148.34+1.4609 \times 10^{7} e^{\left(\frac{-18081}{T}\right)}
$$


where

$\mathrm{H}(\mathrm{T})=$ Enthalpy $(\mathrm{J} / \mathrm{mol})$.

$\mathrm{H}(\mathrm{T})-\mathrm{H}(298)=\quad$ Enthalpy at Temperature T Relative to Enthalpy at $298 \mathrm{~K}(\mathrm{~J} / \mathrm{mol})$

$\theta \quad=\quad$ Einstein Temperature of UN $(367.5 \mathrm{~K})$

$\mathrm{T}=$ Temperature $(\mathrm{K})$

Valid for $298 \leq \mathrm{T} \leq 2628 \mathrm{~K}$.

Temperature dependence in both equations is identical.

Stable for all temperatures.

Could be used to produce reasonable estimates at temperatures.

Hayes, S. L., J. K. Thomas and K. L. Peddicord, J. Nucl. Mater., 171, 300, 1990.

$H(T)-H(298)=3.007 \times 10^{-9} T^{4}-1.387 \times 10^{-5} T^{3}+0.2939 T^{2}+30.38 T-9438-\left(\frac{5.637 \times 10^{5}}{T}\right)$

where

$\mathrm{H}(\mathrm{T})-\mathrm{H}(298) \quad=\quad$ Enthalpy $(\mathrm{J} / \mathrm{mol})$

$\mathrm{T}=$ Temperature $(\mathrm{K})$

Valid for $0 \leq \mathrm{T} \leq 2650 \mathrm{~K}$

Thetford, R. T. and M. Mignanelli, The Chemistry and Physics of Modeling Nitride Fuels for Transmutation, J. Nucl. Mater., 320, 44 (2003)

Reference(s) as cited by author(s):

Hayesm, S. L., J. K. Thomas, K. L. Peddicord, J. Nucl. Mater., 171 (1990) 300

Tagawa, H., J. Nucl. Matter, 51 (1974) 78

Samsonov, G. V., I. M. Vinitskii, Handbook of Refactory Compoundsm IFI/Plenum Data Company, New York, 1980

Tagawa, H., Phase Relations and Thermodynamic Properties of the Uranium-Nitrogen System, J. Nuc1. Mater., 51, 78 (1974)

$-70.4 \mathrm{kcal} / \mathrm{mole} \quad$ at $298 \mathrm{~K}$ 
Olson, W. M. and R. N. R. Mulford, The Decomposition and Melting Point of Uranium Mononitride, J. Phys. Chem., 67, 952 (1963)

$H(T)-H(298.15 K)=11.681 T+1.3291 \times 10^{-3} T^{2}+\frac{9.812 \times 10^{4}}{T}-3.930 \times 10^{3}$

where

$\mathrm{H}(\mathrm{T})-\mathrm{H}(298.15 \mathrm{~K}) \quad=\quad$ Enthalpy $(\mathrm{cal} / \mathrm{mol})$

$\mathrm{T}=$ Temperature $(\mathrm{K})$

Valid for $298 \leq \mathrm{T} \leq 1700 \mathrm{~K}$

Oetting, F. L. and J. M. Leitnaker, The Chemical Thermodynamic Properties of Nuclear Materials, J. Chem. Thermo., 4, 199 (1972)

$2167 \mathrm{cal} / \mathrm{mol} \quad$ at $298 \mathrm{~K}$

Counsell, J. F., R. M. Dell and J. F. Martin, Thermodynamic Properties of Uranium Compounds, Trans. Faraday Soc., 62, 1736 (1966)

\subsubsection{Entropy}

$S(T)=\frac{51.14\left(\frac{367.5}{T}\right)}{e^{\left(\frac{367.5}{T}\right)}-1}-51.14 \ln \left(1-e^{\left(\frac{-367.5}{T}\right)}\right)+9.491 \times 10^{-3} T+16.31$

where

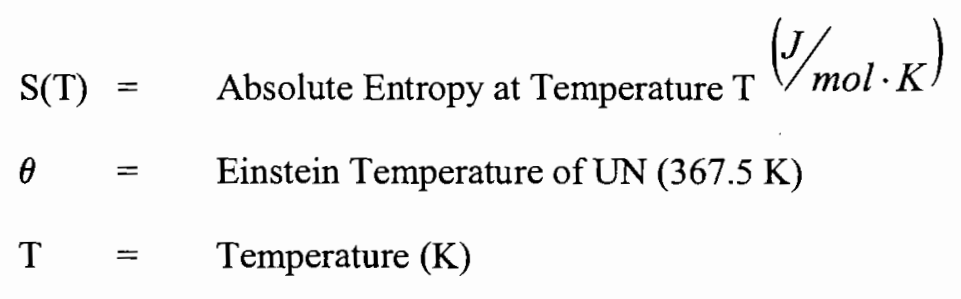

Valid for $298 \leq \mathrm{T} \leq 2628 \mathrm{~K}$

Stable at high temperatures.

Should produce reasonable estimates above $2628 \mathrm{~K}$.

Should not be used below $298 \mathrm{~K}$

Hayes, S. L., J. K. Thomas and K. L. Peddicord, J. Nucl. Mater., 171, 300, 1990.
$-21.9 \mathrm{cal} / \mathrm{mol} \cdot \mathrm{K}$
at $298 \mathrm{~K}$ 
Olson, W. M. and R. N. R. Mulford, The Decomposition and Melting Point of Uranium Mononitride, J. Phys. Chem., 67, 952 (1963)

Reference(s) as cited by author(s):

Rand, M. H. and O. Kubaschewski, Document AERE-T-3487, "Thermochemical Properties of Uranium Compounds," United Kingdom Atomic Energy Authority, 1960

Gross, P. M., et. al., Paper SM-26/7 at Symposium on the Thermodynamics of Nuclear Materials, Vienna, 1962. To be published by the International Atomic Energy Agency, Vienna

$14.87 \mathrm{ca} / \mathrm{mol} \cdot \mathrm{K} \quad$ at $298.15 \mathrm{~K}$

Counsell, J. F., R. M. Dell and J. F. Martin, Thermodynamic Properties of Uranium Compounds, Trans. Faraday Soc., 62, $1736(1966)$

Oetting, F. L., and J. M. Leitnaker, The Chemical Thermodynamic Properties of Nuclear Materials, J. Chem. Thermo., 4, 199 (1972)

H. Tagawa, Phase Relations and Thermodynamic Properties of the Uranium-Nitrogen System, J. Nucl. Mater., 51, 78 (1974)

\subsubsection{Gibb's Free Energy}

$G(T)=51.14 T \ln \left(1-e^{\left(\frac{-367.5}{T}\right)}\right)-4.746 \times 10^{-3} T^{2}-16.31+1.461 \times 10^{7} e^{\left(\frac{-18081}{T}\right)}$

where

$$
\begin{array}{ll}
\mathrm{G}(\mathrm{T}) & =\text { Gibb's Free Energy }(\mathrm{J} / \mathrm{mol}) \\
\mathrm{T} & =\text { Temperature }(\mathrm{K})
\end{array}
$$

Valid for $298 \leq \mathrm{T} \leq 2628 \mathrm{~K}$.

Stable at high temperatures.

Produces reasonable estimates of Gibb's Free Energy above $2628 \mathrm{~K}$.

Hayes, S. L., J. K. Thomas and K. L. Peddicord, J. Nucl. Mater., 171, 300, 1990.

$$
F E F=-51.14 \ln \left(1-e^{\left(\frac{-367.5}{T}\right)}\right)+4.746 \times 10^{-3} T+\frac{8148.34}{T}+16.31-\frac{1.461 \times 10^{7}}{T} e^{\left(\frac{-18081}{T}\right)}
$$

where

$$
\begin{aligned}
& \mathrm{FEF}=\text { Free Energy Function }(\mathrm{J} / \mathrm{mol} \cdot \mathrm{K}) \\
& \mathrm{T}=\text { Temperature }(\mathrm{K})
\end{aligned}
$$


Valid for $298 \leq \mathrm{T} \leq 2628 \mathrm{~K}$.

Stable at high temperatures.

Produces reasonable estimates of Free Energy Function above $2628 \mathrm{~K}$.

Hayes, S. L., J. K. Thomas and K. L. Peddicord, J. Nucl. Mater., 171, 300, 1990.

$$
F E F=-2.9114 \times 10^{5}+66.838 T+1.1554 \times 10^{-2} T^{2}-2.1086 \times 10^{-6} T^{3}
$$

where

$$
\begin{aligned}
& \mathrm{FEF}=\text { Free Energy of Formation }(\mathrm{J} / \mathrm{mol}) \\
& \mathrm{T}=\text { Temperature. }
\end{aligned}
$$

Johnson, C. E., Thermophysical and Mechanical Properties of Advanced Carbide and Nitride Fuels, ANL-AFP-27, June 1976

\subsubsection{Heat Capacity}

$$
C_{P}=11.171+2.364 \times 10^{-3} T-\left(\frac{8.404 \times 10^{4}}{T^{2}}\right)
$$

where

$$
\begin{aligned}
\mathrm{CP} & =\text { Heat Capacity }\left(\mathrm{cal} / \mathrm{mol} \cdot{ }^{\circ} \mathrm{C}\right) \\
\mathrm{T} & =\text { Temperature }\left({ }^{\circ} \mathrm{C}\right)
\end{aligned}
$$

Valid for temperatures $0 \leq \mathrm{T} \leq 1200^{\circ} \mathrm{C}$.

Composition: $\quad 5.40 \mathrm{w} / \mathrm{o} \mathrm{N}_{2}$

$$
\begin{aligned}
& 950 \text { ppm C } \\
& 640 \text { ppm O }
\end{aligned}
$$

M.A. DeCrescente, M.S. Freed and S.D. Caplow, PWAC-488, "Uranium Nitride Fuel Development," Pratt and Whitney Aircraft-CANEL Oct. 12, 1963

Reference(s) as cited by author(s):

PWAC-1007, “Advanced Materials Program for January and February, 1963,” Pratt and Whitney Aircraft-CANEL

BMI-X-10083, D. L. Keller, "Development of Uranium Mononitride," Quarterly Progress Report for July-September, 1962 (Preliminary), Battelle Memorial Institute. 
$C_{P}=1.203 \times 10^{-8} T^{3}-4.161 \times 10^{-5} T^{2}+0.05877 T+30.38+\left(\frac{5.637 \times 10^{5}}{T^{2}}\right)$

where

$\mathrm{CP}=$ Heat Capacity $(\mathrm{J} / \mathrm{mol} \cdot \mathrm{K})$

$\mathrm{T}=$ Temperature $(\mathrm{K})$

Valid for $0 \leq \mathrm{T} \leq 2650 \mathrm{~K}$

Uncertainties of $\pm 2(\mathrm{~J} / \mathrm{mol} \mathrm{K})$ up to $1500 \mathrm{~K}$ and $\pm 6(\mathrm{~J} / \mathrm{mol} \mathrm{K})$ at $2650 \mathrm{~K}$.

Thetford, R. T. and M. Mignanelli, The Chemistry and Physics of Modeling Nitride Fuels for Transmutation, J. Nucl. Mater., 320, 44 (2003)

Reference(s) as cited by author(s):

Hayesm, S. L., J. K. Thomas, K. L. Peddicord, J. Nucl. Mater., 171 (1990) 289

Tagawa, H., J. Nucl. Mater., 51 (1974) 78

Matsui, T., R. W. Ohse, High Temp. High Press. 19 (1987) 1

$C_{P}=48.8733+11.1211 \times 10^{-3} T-\frac{4.1053 \times 10^{5}}{T}$

where

$\mathrm{CP}=$ Heat Capacity $(\mathrm{J} / \mathrm{mol} \cdot \mathrm{K})$

$\mathrm{T}=$ Temperature

Valid for $298 \leq \mathrm{T} \leq 2500 \mathrm{~K}$

Johnson, C. E., Thermophysical and Mechanical Properties of Advanced Carbide and Nitride Fuels, ANL-AFP-27, June 1976

$C_{P}=12.942+5.4509 \times 10^{-4} T+1.045 \times 10^{-6} T^{2}-\frac{1.62823 \times 10^{5}}{T^{2}}$

where

$$
\begin{array}{lll}
\mathrm{CP} & =\text { Heat Capacity }(\mathrm{cal} / \mathrm{mol} \cdot \mathrm{K}) \\
\mathrm{T} & =\text { Temperature }(\mathrm{K})
\end{array}
$$

Tagawa, H., Phase Relations and Thermodynamic Properties of the Uranium-Nitrogen System, J. Nucl. Mater., 51, 78 (1974) 
$C_{P}=11.681+2.6582 \times 10^{-3} T-\frac{9.812 \times 10^{4}}{T^{2}}$

where

$$
\begin{aligned}
\mathrm{CP} & =\text { Heat Capacity }(\mathrm{cal} / \mathrm{mol} \cdot \mathrm{K}) \\
\mathrm{T} & =\text { Temperature }(\mathrm{K})
\end{aligned}
$$

Valid for $298 \leq \mathrm{T} \leq 1700 \mathrm{~K}$

Oetting, F. L. and J. M. Leitnaker, The Chemical Thermodynamic Properties of Nuclear Materials, J. Chem. Thermo., 4, 199 (1972)

$$
C_{P}=13.32+1.9 \times 10^{-3} T-\frac{2.10 \times 10^{5}}{T^{2}}
$$

where

$$
\begin{aligned}
\mathrm{CP} & =\text { Heat Capacity }(\mathrm{cal} / \mathrm{mol} \cdot \mathrm{K}) \\
\mathrm{T} & =\text { Temperature }(\mathrm{K})
\end{aligned}
$$

Valid for $273 \leq \mathrm{T} \leq 1423 \mathrm{~K}$

Counsell, J. F., R. M. Dell and J. F. Martin, Thermodynamic Properties of Uranium Compounds, Trans.

Faraday Soc., 62, $1736(1966)$

$$
H(T)-H(273)=13.3211 T+5.9302 \times 10^{-4} T^{2}+\frac{2.1025 \times 10^{5}}{T}-4437.23
$$

where

$$
\begin{array}{lll}
\mathrm{H}(\mathrm{T})-\mathrm{H}(273) & = & \text { Specific Heat }(\mathrm{cal} / \mathrm{g} \cdot \mathrm{mol} \mathrm{C}) \\
\mathrm{T} & = & \text { Temperature }(\mathrm{K})
\end{array}
$$

Speidel, E. O. and D. L. Keller, Fabrication and Properties of Hot-Pressed Uranium Mononitride, BMI-1633 (1963)

\subsubsection{Specific Heat}

$$
C_{P}=51.14\left(\frac{367.5}{T}\right)^{2} \frac{e^{\left(\frac{367.5}{T}\right)}}{\left(e^{\left(\frac{367.5}{T}\right)}-1\right)^{2}}+9.491 \times 10^{-3} T+\frac{2.6415 \times 10^{11}}{T^{2}} e^{\left(\frac{-18081}{T}\right)}
$$


where

$$
\begin{aligned}
& \mathrm{CP}=\text { Specific Heat }(\mathrm{J} / \mathrm{mol} \cdot \mathrm{K}) \\
& \mathrm{T}=\text { Temperature }(\mathrm{K})
\end{aligned}
$$

Valid for $298 \leq \mathrm{T} \leq 2628 \mathrm{~K}$

Reasonable estimates should be possible above $2628 \mathrm{~K}$

Hayes, S. L., J. K. Thomas and K. L. Peddicord, J. Nucl. Mater., 171, 300, 1990.

$$
C_{P}=13.32+1.19 \times 10^{-3} T-\frac{2.10 \times 10^{5}}{T^{2}}
$$

where

$$
\begin{aligned}
\mathrm{CP} & =\text { Specific Heat }(\mathrm{cal} / \mathrm{g} \cdot \mathrm{mol}) \\
\mathrm{T} & =\text { Temperature }(\mathrm{K})
\end{aligned}
$$

Valid for $273 \leq \mathrm{T} \leq 1423 \mathrm{~K}$

Speidel, E. O. and D. L. Keller, Fabrication and Properties of Hot-Pressed Uranium Mononitride, BMI-1633 (1963)

\subsubsection{Heat of Formation}

$$
-295.81 \mathrm{~kJ} / \mathrm{mol} \quad \text { at } 298 \mathrm{~K}
$$

Not Possible to Clearly Identify Trends.

Approximate Values.

$$
\begin{array}{ll}
-294.56 \pm 1.55 \mathrm{~kJ} / \mathrm{mol} & 300 \leq \mathrm{T} \leq 1000 \mathrm{~K} \\
-302.53 \pm 4.27 \mathrm{~kJ} / \mathrm{mol} & 1100 \leq \mathrm{T} \leq 2400 \mathrm{~K} \\
-289.69 \pm 6.8 \mathrm{~kJ} / \mathrm{mol} & 2500 \leq \mathrm{T} \leq 3000 \mathrm{~K}
\end{array}
$$

Johnson, C. E., Thermophysical and Mechanical Properties of Advanced Carbide and Nitride Fuels, ANL-AFP-27, June 1976

Tagawa, H., Phase Relations and Thermodynamic Properties of the Uranium-Nitrogen System, J. Nucl. Mater., 51, 78 (1974)

\subsubsection{Heat of Fusion}

$$
53.35 \mathrm{~kJ} / \mathrm{mol} \quad \text { (estimated) }
$$


Johnson, C. E., Thermophysical and Mechanical Properties of Advanced Carbide and Nitride Fuels, ANL-AFP-27, June 1976

\subsubsection{Heat of Sublimation}

$733.25 \mathrm{~kJ} / \mathrm{mol}$

Valid for $2400 \leq \mathrm{T} \leq 2600 \mathrm{~K}$

Johnson, C. E., Thermophysical and Mechanical Properties of Advanced Carbide and Nitride Fuels, ANL-AFP-27, June 1976

\subsubsection{Heat of Vaporization}

$$
678 \pm 15 \mathrm{~kJ} / \mathrm{mol} \quad \text { (estimated) }
$$

Johnson, C. E., Thermophysical and Mechanical Properties of Advanced Carbide and Nitride Fuels, ANL-AFP-27, June 1976

\subsubsection{Thermal Conductivity}

Polynomial Regression of the data produces.

$$
\lambda=-0.0002 \mathrm{~T}^{6}+0.005 \mathrm{~T}^{5}-0.0609 \mathrm{~T}^{4}+0.3792 \mathrm{~T}^{3}-1.2708 \mathrm{~T}^{2}+2.1685 \mathrm{~T}-1.2208
$$

where

$$
\begin{aligned}
& \lambda=\text { Thermal Conductivity }\left(\mathrm{W} / \mathrm{cm} \cdot{ }^{\circ} \mathrm{C}\right) \\
& \mathrm{T}=\text { Temperature }\left({ }^{\circ} \mathrm{C}\right)
\end{aligned}
$$

With a correlation coefficient of $R^{2}=0.9997$.

Composition: $\quad 5.32 \mathrm{w} / \mathrm{o}_{2}$

$700 \mathrm{ppm} \mathrm{C}$

$850 \mathrm{ppm} \mathrm{O}$

DeCrescente, M. A., M. S. Freed and S. D. Caplow, PWAC-488, "Uranium Nitride Fuel Development," Pratt and Whitney Aircraft-CANEL Oct. 12, 1963

Reference(s) as cited by author(s):

PWAC-481, B. A. Hayes and M. A. DeCrescente, "Thermal Conductivity of UN," September 30, 1965, Pratt and Whitney Aircraft-CANEL.

BMI-1633, E. O. Speidel and D. L. Keller, "Fabrication and Properties of Hot Pressed Uranium Mononitride," Battelle Memorial Institute. 
$\lambda=1.864 e^{-2.14 P} T^{0.361}$

where

$$
\begin{array}{ll}
\lambda & =\text { Thermal Conductivity }(W / m \cdot K \\
\mathrm{P} & =\text { Porosity (volume fraction) } \\
\mathrm{T} & =\text { Fuel Temperature (K) }
\end{array}
$$

Valid for $298 \leq \mathrm{T} \leq 1923 \mathrm{~K}$ and $0 \leq \mathrm{P} \leq 20 \%$

Hayes, S. L., J. K. Thomas and K. L. Peddicord, J. Nucl. Mater., 171, 289, 1990.

$$
K=\left(\frac{1+P}{1-P}\right) 1.37 T^{0.41}
$$

where

$$
\begin{aligned}
& \mathrm{K}=\text { Thermal Conductivity }(\mathrm{W} / \mathrm{m} \cdot \mathrm{K}) \\
& \mathrm{P}=\text { Porosity (Volume Fraction) } \\
& \mathrm{T}=\text { Temperature }(\mathrm{K})
\end{aligned}
$$

El-Genk, M. S., S. B. Ross and R. B. Matthews, "Uranium Nitride Fuel Swelling and Thermal Conductivity Correlations," Transactions, 4th Symposium on Space Nuclear Power Systems, Albuquerque, NM, January 1987

$K=0.31 \times 10^{-4} T+0.029$

where

$$
\begin{aligned}
\mathrm{K} & =\text { Thermal Conductivity }\left(\mathrm{cal} / \mathrm{sec} \cdot \mathrm{cm} \cdot{ }^{\circ} \mathrm{C}\right) \\
\mathrm{T} & =\text { Temperature }\left({ }^{\circ} \mathrm{C}\right)
\end{aligned}
$$

Speidel, E. O. and D. L. Keller, Fabrication and Properties of Hot-Pressed Uranium Mononitride, BMI-1633 (1963)

Moore, J. P., W. Fulkerson and D. L. McElroy, Thermal Conductivity, Electrical Resistivity, and Seebeck Coefficient of Uranium Mononitride, J. Am. Ceram. Soc., 53, 76 (1970)

Endebrock, R. W., E. L. Foster Jr. and D. L. Keller, Preparation and Properties of Cast UN, BMI-1690 (EURAEC-1206) (1964)

Hayes, B. A. and M. A. DeCrescente, Thermal Conductivity and Electrical Resistivity of Uranium Mononitride, PWAC-481 (1965) 
$K=0.02519+4.772 \times 10^{-5} T-1.4227 \times 10^{-8} T^{2}$

where

$$
\begin{aligned}
& \mathrm{K}=\text { Thermal Conductivity }\left(\mathrm{cal} / \mathrm{sec} \cdot \mathrm{cm} \cdot{ }^{\circ} \mathrm{C}\right) \\
& \mathrm{T}=\text { Temperature }\left({ }^{\circ} \mathrm{C}\right) \\
& 100 \% \text { Theoretical Density }
\end{aligned}
$$

Seth, A. and L. Leibowits, Thermal Conductivity Values for Advanced Fuels, ANL-AFP-3 (1974)

\subsubsection{Thermal Emissivity}

0.65 (estimated)

Johnson, C. E., Thermophysical and Mechanical Properties of Advanced Carbide and Nitride Fuels, ANL-AFP-27, June 1976

\subsubsection{Thermal Expansion}

Linear Regression of the data produces.

$$
\frac{\Delta L}{L}=0.0091 T-3.1201
$$

where

$$
\begin{aligned}
\frac{\Delta L}{L} & =\text { Thermal Expansion } \\
\mathrm{T} & =\text { Temperature }\left({ }^{\circ} \mathrm{C}\right)
\end{aligned}
$$

With a correlation coefficient of $\mathrm{R}^{2}=0.997$

Composition: $\quad 5.31 \mathrm{w} / \mathrm{o} \mathrm{N}_{2}$

4100 ppm C

$1250 \mathrm{ppm} \mathrm{O}$

DeCrescente, M. A., M. S. Freed and S. D. Caplow, PWAC-488, "Uranium Nitride Fuel Development," Pratt and Whitney Aircraft-CANEL Oct. 12, 1963

Reference(s) as cited by author(s):

PWAC-1018, “Advanced Materials Program for November and December, 1964," Pratt and Whitney Aircraft-CANEL.

BMI-1633, E. O. Speidel and D. L. Keller, "Fabrication and Properties of Hot Pressed Uranium Mononitride," Battelle Memorial Institute. 
ORNL-3670, “Annual Progress Report for Period Ending June 30, 1964,” Materials and Ceramic Div., Oak Ridge National Laboratory.

$$
\frac{\Delta L}{L}=-0.212+6.541 \times 10^{-4} T+2.526 \times 10^{-7} T^{2}-4.010 \times 10^{-11} T^{3}
$$

where

$$
\begin{aligned}
\frac{\Delta L}{L} & =\text { Thermal Expansion }(\% \text { Change in Length from } 293 \mathrm{~K}) \\
\mathrm{T} & =\text { Temperature }(\mathrm{K})
\end{aligned}
$$

Thermophysical Properties of Matter Vol. 13, p. 1152.

Mean Linear Thermal Expansion Coefficient.

$$
\alpha_{\mathrm{m}}=7.096 \times 10^{-6}+1.409 \times 10^{-9} \cdot \mathrm{T}
$$

where

$$
\begin{aligned}
& \alpha_{\mathrm{m}}=\text { Mean Linear Thermal Expansion Coefficient }\left(K^{-1}\right) \\
& \mathrm{T}=\text { Temperature }(\mathrm{K})
\end{aligned}
$$

Valid from $298 \leq \mathrm{T} \leq 2523 \mathrm{~K}$

Hayes, S. L., J. K. Thomas and K. L. Peddicord, J. Nucl. Mater., 171, 262, 1990.

$$
\alpha_{m}=\frac{\left(\frac{\Delta L}{L}\right) \times 10^{-2}}{T-293}
$$

where

$$
\begin{aligned}
& \alpha_{m}=\text { Mean Coefficient of Thermal Expansion }(\mathrm{in} / \mathrm{in} / \mathrm{K}) \\
& \mathrm{T}=\text { Temperature }(\mathrm{K})
\end{aligned}
$$

Thermophysical Properties of Matter Vol. 13, p. 1152.

\subsubsection{Instantaneous Coefficient of Thermal Expansion.}

$\alpha_{I}=6.541 \times 10^{-6}+5.052 \times 10^{-9} T-1.203 \times 10^{-12} T^{2}$

where 
$\begin{aligned} \alpha_{I} & =\text { Instantaneous Coefficient of Thermal Expansion }(\mathrm{in} / \mathrm{in} / \mathrm{K}) \\ \mathrm{T} & =\text { Temperature }(\mathrm{K})\end{aligned}$

Thermophysical Properties of Matter Vol. 13, p. 1152.

Speidel, E. O., and D. L. Keller, Fabrication and Properties of Hot-Pressed Uranium Mononitride, BMI-1633 (1963)

\subsection{Performance Properties}

\subsubsection{Fission Gas Release}

Fission gas release models have been developed as a result of various nitride irradiation studies. Storms, 1988, performed a review of the available data during the SP-100 fuel development program. He developed a fit of the data as a function of temperature, burnup, and theoretical density. It is generally accepted that the available data does not correlate well due to a number of factors, most related to the wide variety of test conditions, fuel fabrication techniques, post processing, and irradiation conditions. Storms' review and generation of a fit was based on his assessment of the data with regards to the similarity of fabrication, processing, and test conditions. The following correlation was developed following selection of data.

$$
R=\frac{100}{e^{\left(0.0025\left\{\frac{90 T D^{0.77}}{B^{0.09}-T}\right\}\right)}+1}
$$

where

$$
\begin{aligned}
& \mathrm{R}=\text { Fission Gas Release }(\%) \\
& \mathrm{TD}=\text { Theoretical Density }(\%) \\
& \mathrm{B}=\text { Burnup (Atom } \%) \\
& \mathrm{T}=\text { Temperature }(\mathrm{K})
\end{aligned}
$$

Storms, E. K., An Equation Which Describes Fission Gas Release from UN Reactor Fuel, J. Nucl. Mater., $158,119-29(1988)$ 


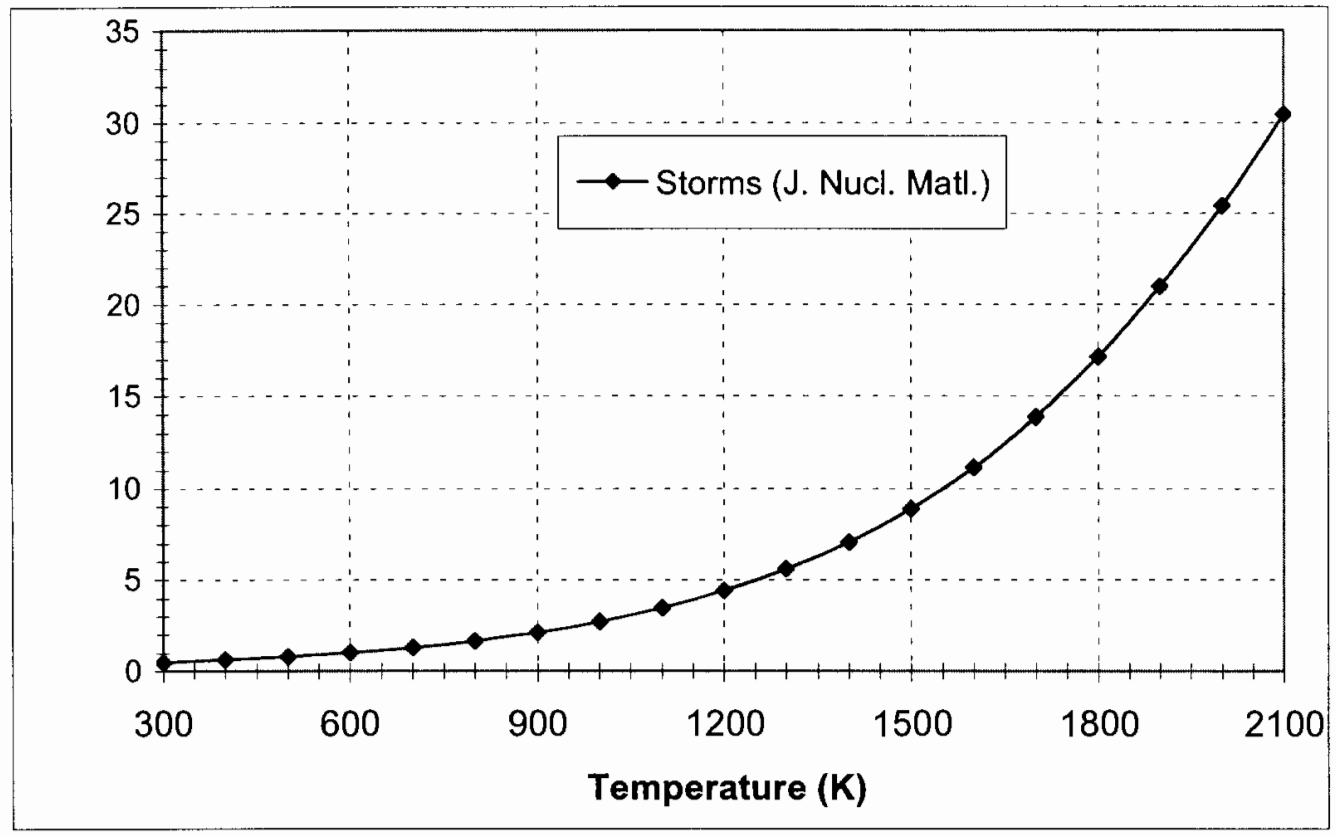

Figure 7. Percent release as a function of temperature for 5\% Burnup and $95 \%$ TD.

\subsubsection{Restrained Swelling}

The correlation for restrained swelling is taken from, Ma, B.M, 1983. This correlation is based upon the external clad restrained swelling. Claddings included in the correlation include W-25Re and W. The correlation by Ma seems to provide values fairly similar to those developed in the unrestrained swelling correlation by Anderson, 1983.

$$
S=1396 e^{-1.095 \cdot\left(\frac{10000}{T}\right)}
$$

where

$$
\begin{array}{lll}
\mathrm{S} & = & \text { Restrained Swelling (\%) } \\
\mathrm{T} & = & \text { Temperature }(\mathrm{K})
\end{array}
$$

Anderson, R. V., ESG-DOE-13413, Power Plant System Assessment, Final Report. SP-100 Program, October 1983, Rockwell International Energy Systems Group Report.

$$
\frac{\Delta V}{V}=4.768 \times 10^{-11} T^{3.12} B^{0.83} \rho^{0.5}
$$

where

$$
\begin{array}{lll}
\frac{\Delta V}{V}= & \text { Restrained Swelling (\%) } \\
\mathrm{T}= & \text { Temperature }(\mathrm{K})
\end{array}
$$




$$
\begin{array}{ll}
\mathrm{B} & =\text { Burnup (atom \%) } \\
\rho & =\text { Fuel Density }(\% \text { Theoretical) }
\end{array}
$$

UN Fuel with a Nb-1Zr Cladding.

El-Genk, M. S., S. B. Ross and R. B. Matthews, "Uranium Nitride Fuel Swelling and Thermal Conductivity Correlations" in: Trans. 4th Symposium on Space Nuclear Power Systems, Albuquerque, NM, Jan. 12-16 1987, p. 313-17

\subsubsection{Unrestrained Swelling}

$$
\begin{aligned}
& S=0.8 B+C_{1}\left(1-e^{\left(-C_{2} B\right)}\right) \\
& C_{1}=10+\frac{24}{1+e^{\left(\frac{1400-T}{74}\right)}} \\
& C_{2}=0.06+8.25 \times 10^{3} e^{\left(\frac{-2.027 \times 10^{4}}{T}\right)} \\
& T=\left(1-\frac{t_{T \max }}{t}\right) T_{m}+\frac{t_{\text {max }}}{t} T_{\text {max }}
\end{aligned}
$$

where

$$
\begin{aligned}
& \mathrm{S}=\quad \text { Unrestrained Swelling (vol\%) } \\
& \mathrm{B}=\text { Burnup (\%) } \\
& \mathrm{T}=\text { Fuel Temperature (K) } \\
& \mathrm{Tm}=\text { Time-Averaged Temperature }(\mathrm{K}) \\
& \operatorname{Tmax}=\text { Maximum Fuel Temperature }(\mathrm{K}) \\
& \mathrm{t}=\text { Irradiation Period } \\
& \mathrm{t}=\text { Time at which Maximum Fuel Temperature was Observed }
\end{aligned}
$$

Valid from $500 \leq \mathrm{T} \leq 2000 \mathrm{~K}$.

Zimmermann, H., Investigation of Swelling of U-Pu Mixed Carbide, J. Nucl. Mater., $105,56(1982)$ 


\section{PROPERTIES OF ALLOY HT-9 (12CR,1MO,V,W) \\ 3.1 Physical Properties}

\subsubsection{Density}

$\rho=7.874-3.23 \times 10^{-4} T$

where

$$
\begin{aligned}
\rho & =\text { Density }\left(\mathrm{g} / \mathrm{cm}^{3}\right) \\
\mathrm{T} & =\text { Temperature }(\mathrm{K})
\end{aligned}
$$

Valid for $273 \leq T \leq 1073 \mathrm{~K}$.

Calculations for temperatures above $1073 \mathrm{~K}$ cannot be made with this equation due to the ferriteto-austenite transition which creates volumetric strain.

AFCI Materials Handbook.

References cited by author(s):

Alloy Properties Databook, Hanford Engineering Development Laboratory, HEDL-TC-293, Rev. 5.

\subsubsection{Melting Point}

$1743 \mathrm{~K}$ to $1753 \mathrm{~K}$

AFCI Materials Handbook

Reference(s) as cited by author(s):

ASM Metals Handbook, $9^{\text {th }}$ Edition, Vol. 3, p. 35, American Society for Metals, Metals Park, OH, 1980.

\subsection{Mechanical Properties}

\subsubsection{Creep}

Thermal Creep

$\varepsilon_{T}=\varepsilon_{T P(\text { Pr imary) }}+\varepsilon_{T S(\text { Steady }- \text { State) }}+\varepsilon_{T T(\text { Tertiary })}$

$\varepsilon_{T P}=\left[13.4+e^{\left(\frac{-15027}{1.987 T}\right)} \bar{\sigma}+8.43 \times 10^{-3}+e^{\left(\frac{-26651}{1.987 T}\right)} \bar{\sigma}^{4}+4.08 \times 10^{18}+e^{\left(\frac{-89167}{1.987 T}\right)} \bar{\sigma}^{0.5} \times\left(1-e^{\left(-1.6 \times 10^{-6} t\right)}\right)\right]$ 
$\varepsilon_{T S}=\left[1.17 \times 10^{9}+e^{\left(\frac{-83142}{1.987 T}\right)} \bar{\sigma}^{2}+8.33 \times 10^{9}+e^{\left(\frac{-108276}{1.987 T}\right)} \bar{\sigma}^{5}\right]$

$\varepsilon_{T T}=9.53 \times 10^{21}+e^{\left(\frac{-282700}{1.987 T}\right)} \bar{\sigma}^{10} t^{4}$

where

$$
\begin{array}{rll}
\bar{\sigma} & = & \text { Effective Stress (MPa) } \\
\mathrm{T} & =\text { Temperature (K) } \\
\mathrm{t} & =\text { Time (s) }
\end{array}
$$

Valid for $623 \leq \mathrm{T} \leq 1023 \mathrm{~K}$ and $0 \leq \bar{\sigma} \leq 250 \mathrm{Mpa}$.

Thermal Creep at constant temperature and stress

$$
\dot{\varepsilon}_{T}=\dot{\varepsilon}_{T P}+\dot{\varepsilon}_{T S}+\dot{\varepsilon}_{T T}
$$$$
\dot{\varepsilon}_{T P}=\left[13.4+e^{\left(\frac{-15027}{1.987 T}\right)} \bar{\sigma}+8.43 \times 10^{-3}+e^{\left(\frac{-26451}{1.987 T}\right)} \bar{\sigma}^{4}+4.08 \times 10^{18}+e^{\left(\frac{-89167}{1.987 T}\right)} \bar{\sigma}^{0.5}\right]\left(1-e^{\left(-1.6 \times 10^{-6} t\right)}\right)
$$$$
\dot{\varepsilon}_{T S}=\left[1.17 \times 10^{9}+e^{\left(\frac{-83142}{1.987 T}\right)} \bar{\sigma}^{2}+8.33 \times 10^{9}+e^{\left(\frac{-108276}{1.987 T}\right)} \bar{\sigma}^{5}\right] t
$$

$\dot{\varepsilon}_{T T}=4\left(9.53 \times 10^{2 \mathrm{l}}\right)+e^{\left(\frac{-282700}{1.987 T}\right)} \bar{\sigma}^{10} t^{3}$

where

$$
\begin{array}{rll}
\bar{\sigma} & = & \text { Effective Stress (MPa) } \\
\mathrm{T} & =\text { Temperature (K) } \\
\mathrm{t} & =\text { Time (s) }
\end{array}
$$

Valid for $623 \leq \mathrm{T} \leq 1023 \mathrm{~K}$ and $0 \leq \bar{\sigma} \leq 250 \mathrm{Mpa}$.

\subsubsection{Irradiation-Induced Creep}

$$
\varepsilon_{I}=\left[1.83 \times 10^{-4}+2.59 \times 10^{14} e^{\left(\frac{-Q}{1.987 T}\right)}\right] \varphi \bar{\sigma}^{1.3}
$$


where

$$
\begin{aligned}
\epsilon_{\mathrm{I}} & =\text { Effective Stress (\%) } \\
\bar{\sigma} & =\text { Effective Stress (MPa) } \\
\phi & =\text { Neutron Fluence }\left(10^{22} \mathrm{n} / \mathrm{cm}^{2}\right)(\mathrm{E}>0.1 \mathrm{MeV}) \\
\mathrm{T} & =\text { Temperature }(\mathrm{K})
\end{aligned}
$$

Valid for $623 \leq \mathrm{T} \leq 1023 \mathrm{~K}$ and $0 \leq \bar{\sigma} \leq 250 \mathrm{MPa}$

\subsubsection{Total Creep}

$\varepsilon=\varepsilon_{I}+\varepsilon_{T}$

AFCI Materials Handbook.

References cited by author(s):

Puigh, R. J., In-Reactor Stress Rupture Data for MOTA after Peak Fluence of $9.6 \times 10^{22} \mathrm{n} / \mathrm{cm}^{2}$ (Through Cycle 4 Irradiation), Hanford Engineering Development Laboratory, HEDL-TC-160-42, 1984.

Shober, F. R., Physical and Mechanical Properties of Alloy HT-9 Used in the Design Analysis of the Core Demonstration Experiment, Hanford Engineering Development Laboratory, HEDL-TC-2845, July 1986.

Toloczko, M. B. and F. A. Garner, "Variability of Irradiation Creep and Swelling of HT9 Irradiated to High Neutron Fluence at $400^{\circ} \mathrm{C}-600^{\circ} \mathrm{C}$," Effects of Irradiation on Materials: $18^{\text {th }}$ International Symposium, ASTM 1325, 1998.

Toloczko, M. B., B. R. Grambau, F. A. Garner and K. Abe, "Comparison of Thermal Creep and irradiaton Creep of HT9 Pressurized Tubes at Test Temperatures from $\sim 490^{\circ} \mathrm{C}$ to $605^{\circ} \mathrm{C}$," Effects of Radiation on Materials: 20 International Symposium, ASTM STP 1405, 2002.

\subsubsection{Modulus of Elasticity}

Correlation from Alloy Properties Databook.

$$
E=41.51-1.0229 \times 10^{-1} T
$$

where

$$
\begin{array}{rll}
\mathrm{E} & =\text { Modulus of Elasticity }(\mathrm{GPa}) \\
\mathrm{T} & =\text { Temperature }(\mathrm{K})
\end{array}
$$

Valid for $273 \leq \mathrm{T} \leq 1073 \mathrm{~K}$.

Correlation developed from data from Sandvik. 
$E=248.72+9.2937 \times 10^{-2} T$

where

$\mathrm{E}=$ Modulus of Elasticity $(\mathrm{GPa})$

$\mathrm{T}=$ Temperature $(\mathrm{K})$

Valid for $293 \leq \mathrm{T} \leq 873 \mathrm{~K}$.

AFCI Materials Handbook.

References cited by author(s):

Alloy Properties Databook, Hanford Engineering Development Laboratory, HEDL-TC-293, Rev. 5.

Sandvik HT9 Martensitic Chromium-Molybdenum Steel, Sandvik Steel Catalogue S-1, p. 720 — ENG, May 1981.

\subsubsection{Poisson's Ratio}

$v=\frac{E}{2 G}-1$

where

$$
\begin{array}{lll}
\nu & =\text { Poisson's Ratio } \\
\mathrm{E} & =\text { Modulus of Elasticity } \\
\mathrm{G} & =\text { Modulus of Rigidity }
\end{array}
$$

Valid for $323 \leq \mathrm{T} \leq 1073 \mathrm{~K}$.

AFCI Materials Handbook

References cited by author(s):

Alloy Properties Databook, Hanford Engineering Development Laboratory, HEDL-TC-293, Rev. 5.

\subsubsection{Modulus of Rigidity}

Correlation from Alloy Properties Databook

$G=10.432 \times 10^{4}-53.79 T$

where

$\mathrm{G} \quad=\quad$ Modulus of Rigidity $(\mathrm{MPa})$

$\mathrm{T}=$ Temperature $(\mathrm{K})$ 
Valid for $323 \leq \mathrm{T} \leq 1073 \mathrm{~K}$.

AFCI Materials Handbook

References cited by author(s):

Alloy Properties Databook, Hanford Engineering Development Laboratory, HEDL-TC-293, Rev. 5.

\subsection{Thermal Properties}

\subsubsection{Electrical Resistivity}

$\rho=0.38654+7.477 \times 10^{-4} T$

where

$\rho \quad=\quad$ Electrical Resistivity $(\mu \Omega-\mathrm{cm})$

$\mathrm{T}=$ Temperature $(\mathrm{K})$

Valid for $293 \leq \mathrm{T} \leq 873 \mathrm{~K}$.

AFCI Materials Handbook

References cited by author(s):

Sandvik HT9 Martensitic Chromium-Molybdenum Steel, Sandvik Steel Catalogue S-1, p. 720 — ENG, May 1981.

\subsubsection{Specific Heat}

$C_{P}=0.28953+0.0006 T$

where

$$
\begin{aligned}
& \mathrm{C}_{\mathbf{P}}=\text { Specific Heat }(\mathrm{kJ} / \mathrm{kg} \cdot \mathrm{K}) \\
& \mathrm{T}=\text { Temperature }(\mathrm{K})
\end{aligned}
$$

Valid for $573 \leq \mathrm{T} \leq 1073 \mathrm{~K}$.

$C_{P}=0.26207+0.00057 T$

where

$$
\begin{aligned}
\mathrm{C}_{\mathrm{P}} & =\text { Specific Heat }(\mathrm{kJ} / \mathrm{kg} \cdot \mathrm{K}) \\
\mathrm{T} & =\text { Temperature }(\mathrm{K})
\end{aligned}
$$


Valid for $293 \leq \mathrm{T} \leq 873 \mathrm{~K}$.

AFCI Materials Handbook

References cited by author(s):

Alloy Properties Databook, Hanford Engineering Development Laboratory, HEDL-TC-293, Rev. 5.

Sandvik HT9 Martensitic Chromium-Molybdenum Steel, Sandvik Steel Catalogue S-1, p. 720 ENG, May 1981.

\subsubsection{Thermal Conductivity}

$\lambda=22.927+5.342 \times 10^{-3} T-1.401 \times 10^{-7} T^{2}-4.642 \times 10^{-10} T^{3}$

where

$$
\begin{aligned}
& \lambda=\text { Thermal Conductivity }(W / m \cdot K) \\
& \mathrm{T}=\text { Temperature }(\mathrm{K})
\end{aligned}
$$

Valid for $298 \leq \mathrm{T} \leq 1088 \mathrm{~K}$.

Sandvik's values are $2-4 \%$ lower in the rang of $298 \leq \mathrm{T} \leq 873 \mathrm{~K}$.

AFCI Materials Handbook

References cited by author(s):

Alloy Properties Databook, Hanford Engineering Development Laboratory, HEDL-TC-293, Rev. 5.

Sandvik HT9 Martensitic Chromium-Molybdenum Steel, Sandvik Steel Catalouge S-1, p. 720 - ENG, May 1981.

\subsubsection{Thermal Emissivity}

For oxidized HT-9.

$\varepsilon=0.67498+1.3228 \times 10^{-4} T$

where

$\epsilon \quad=\quad$ Thermal Emissivity

$\mathrm{T}=$ Temperature $(\mathrm{K})$

Valid for $294 \leq \mathrm{T} \leq 1089 \mathrm{~K}$.

For polished HT-9. 
$\varepsilon=0.090514+1.7056 \times 10^{-4} T$

where

$\epsilon \quad=\quad$ Thermal Emissivity

$\mathrm{T}=$ Temperature $(\mathrm{K})$

Valid for $294 \leq \mathrm{T} \leq 1089 \mathrm{~K}$.

AFCI Materials Handbook

References cited by author(s):

Nuclear Systems Materials Handbook, Book 2, Vol. 2, TID-26666, Hanford Engineering Development Laboratory, Richland, Washington.

\subsubsection{Thermal Expansion}

Mean Coefficient of Thermal Expansion.

$\alpha=9.26 \times 10^{-6}+3.8 \times 10^{-9} \mathrm{~T}$

where

$\alpha=$ Mean Coefficient of Thermal Expansion

$\mathrm{T}=$ Temperature $(\mathrm{K})$

Valid for $293 \leq \mathrm{T} \leq 1073 \mathrm{~K}$.

Correlation from Nuclear Systems Handbook for linear thermal expansion

$\frac{\Delta L}{L}=-1.9634+3.524 \times 10^{-3} T+1.1703 \times 10^{-5} T^{2}-4.1642 \times 10^{-9} T^{3}$

where

$$
\begin{aligned}
\frac{\Delta L}{L} & =\text { Strain } \\
\mathrm{T} & =\text { Temperature }(\mathrm{K})
\end{aligned}
$$

Valid for $293 \leq \mathrm{T} \leq 923 \mathrm{~K}$.

Correlation from Nuclear Systems Handbook for mean coefficient of thermal expansion.

$\alpha=7.2867+8.215 \times 10^{-3} T-1.3336 \times 10^{-6} T^{2}-1.222 \times 10^{-9} T^{3}$ 
where

$$
\begin{aligned}
& \alpha=\text { Mean Coefficient of Thermal Expansion }\left(\frac{10^{-6}}{K}\right) \\
& \mathrm{T}=\text { Temperature }(\mathrm{K})
\end{aligned}
$$

Valid for $293 \leq \mathrm{T} \leq 923 \mathrm{~K}$.

Agrees with derived values from Alloy Properties Databook from Sandvik.

Correlation from Nuclear Systems Handbook for instantaneous coefficient of thermal expansion.

$\alpha_{I}=5.1683+1.5615 \times 10^{-2} T-1.1583 \times 10^{-6} T^{2}-5.143 \times 10^{-9} T^{3}$

where

$$
\begin{aligned}
& \alpha_{\mathrm{q}}=\text { Instantaneous Coefficient of Thermal Expansion }\left(\frac{10^{-6}}{K}\right) \\
& \mathrm{T}=\text { Temperature }(\mathrm{K})
\end{aligned}
$$

Valid for $293 \leq \mathrm{T} \leq 923 \mathrm{~K}$.

AFCI Materials Handbook.

References cited by author(s):

Alloy Properties Databook, Hanford Engineering Development Laboratory, HEDL-TC-293, Rev. 5.

Nuclear Systems Materials Handbook, Book 2, Vol. 2, TD-26666, Hanford Engineering Development Laboratory, Richland, Washington.

Sandvik HT9 Martensitic Chromium-Molybdenum Steel, Sandvik Steel Catalouge S-1, p. 720 ENG, May 1981. 


\section{NITRIDE FEA MODEL DESCRIPTION}

As part of the Advanced Fuel Cycle Initiative (AFCI) non-fertile fuel testing program being conducted in the Advanced Test Reactor (ATR), a small modeling effort has been initiated in order to better understand the thermal and mechanical behavior of these fuels (Nitride and Metallic).

Most of the fuel modeling efforts to date have been focused on the Light Water Reactor fuel Uranium Dioxide $\left(\mathrm{UO}_{2}\right)$ using such steady state codes as FRAPCON-3, TRANSURANUS, and COMETHE. To model transient behavior the FRAPTRAN is used. These codes were developed specifically to analyze $\mathrm{UO}_{2}$ and mixed oxide (MOX) fuels, thus they do not contain the proper thermal and mechanical property data base or the appropriate constrictive models to analyze nitride and metallic fuels.

\section{SOLID EDGE 3-D MODEL CONSTRUCTION}

With the increase use of 3D CAD programs to design and develop complex models we have chosen to use the Solid Edge Version 17, 3D CAD software to construct various versions (simple to complex) of the fuel pin model. These models will then be ported into the finite element structural analysis code ABAQUS to be analyzed. A sketch of the Nitride fuel rod that was modeled using Solid Edge is shown in Figure 8.

Solid Edge is configured such that one can build individual parts of the model; then assemble the parts to obtain the overall model to be analyzed. The fuel rodlet shown in Figure 1 was model as several parts in Solid Edge, i.e., fuel pellets, cladding, bond sodium, gas plenum, and endplugs. The parts were then assembled using Solid Edge capability to easily assemble many individual parts into a complete

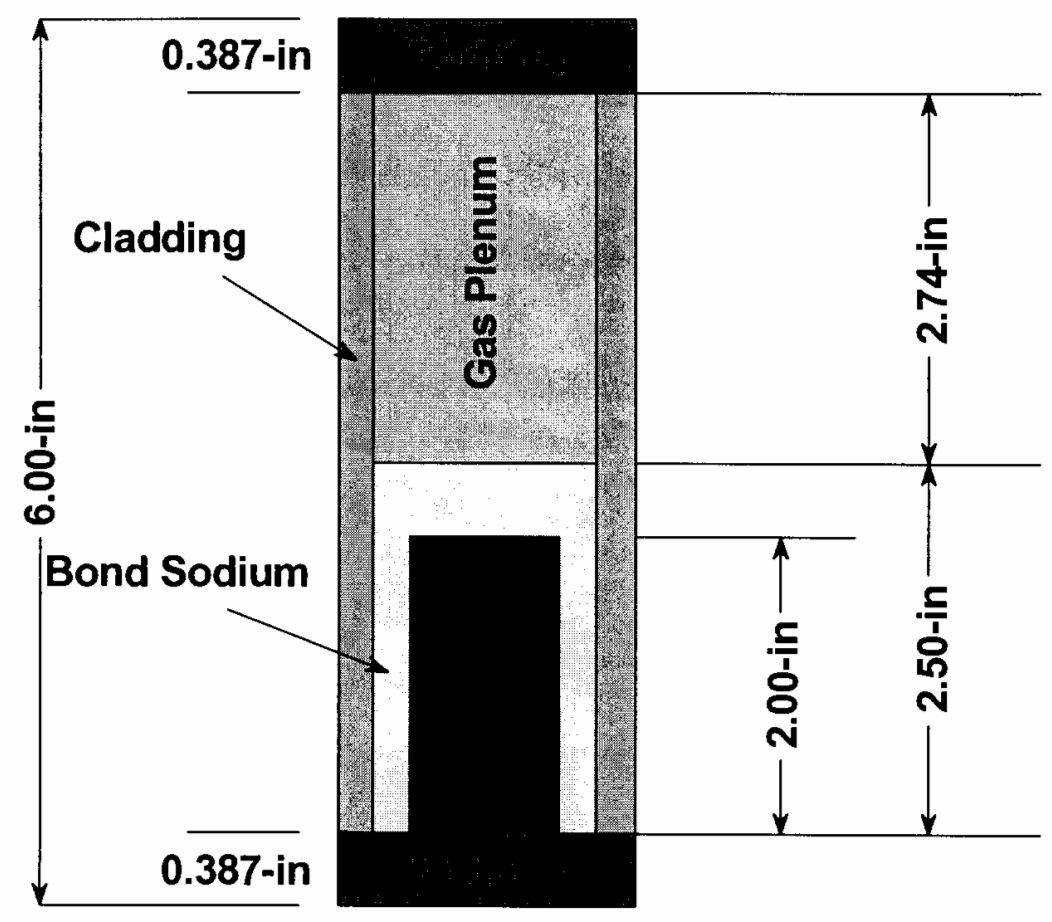

Figure 8. Schematic of nitride fueled rodlet. 
solids model of the fuel rodlet. The complete solid model of the fuel rodlet developed using Solid Edge is shown in Figure 9.

The fuel rodlet in Figure 9 is shown in four different views. The rodlet at the top of the figure is shown with the cladding surrounding the fuel pellets, the bond sodium, the sodium plug and the gas plenum. The rodlet just below is shown with the cladding hidden, thus one see the bonded sodium, the sodium plug and the gas plenum. The rodlet at the bottom of the figure is shown with the bond sodium covering the fuel pellets hidden, thus one sees the stack of ten fuel pellets which are contained in the fuel rodlet, the sodium plug and the gas plenum. The forth view is an end view of the fuel rodlet which shows one end of the fuel pellet stack, the annular bond sodium layer, and the end of the cladding. The model as shown in Figure 9 was then imported into the ABAQUS code where it was meshed.

\section{ABAQUS MESH GENERATION}

The Solid Edge model as described above is imported into the Parts module of the ABAQUS code as an assembled model, however in the Parts module the model is decompose into its individual parts. The relationship of each part with the other parts of the model is retained. However when the model is reassembled in the Assembly module one works only with instances of the part, not the part itself. Part instances are created in the Assemble module. The instances of the parts are then position relative to each other in a global coordinate system using the relationships imported from Solid Edge.

The remaining parts, the bond sodium, the sodium plug, the gas plenum, and the cladding were also created as dependent instance and meshed appropriately. The meshed part for the bond sodium material is shown in Figure 11. The meshed assembled fuel rodlet and fuel assembly with the cladding and bond sodium hidden from view are shown in Figure 10.

The density of the mesh in each part is controlled by what is referred to as mesh seeding. Seeds are markers that one places along the edges of a part to specify the target mesh density in that part. Both the mesh density along the boundary of the part and mesh density in the interior of the part are determined by the seeds along the edges of the part. The seeding can be distributed uniformly along the edges, or they

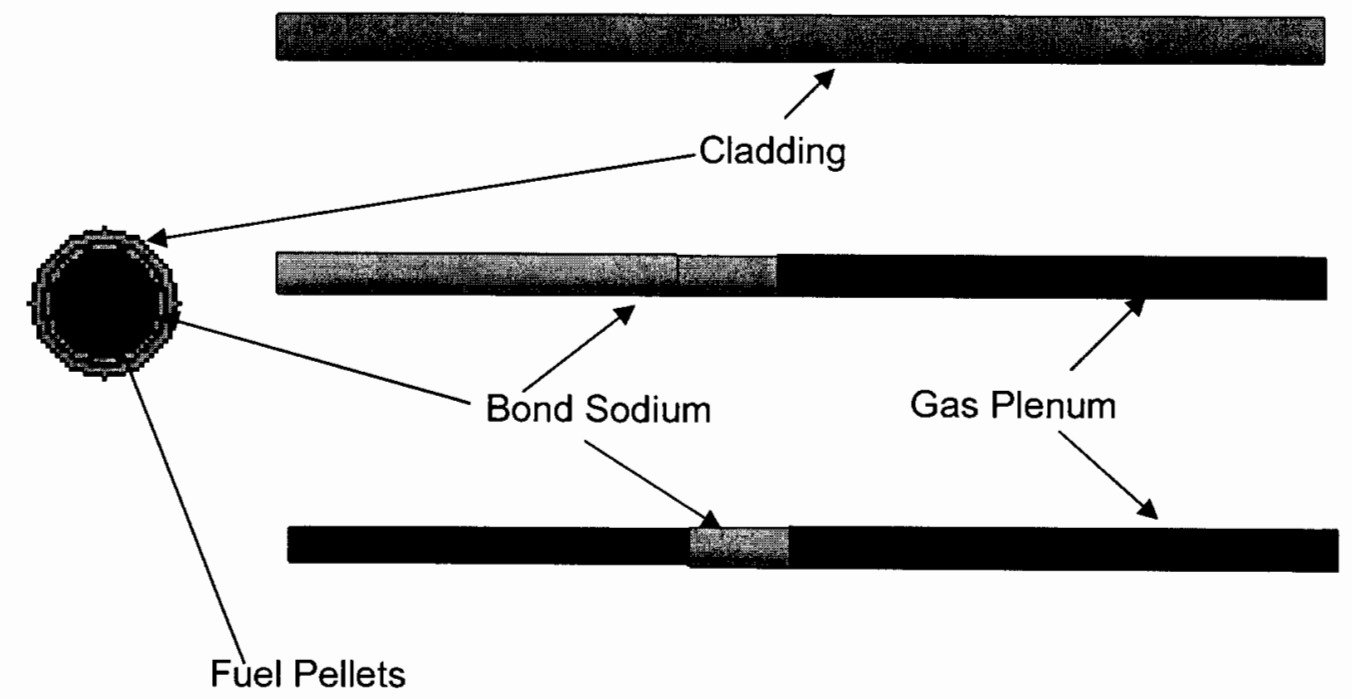

Figure 9. Solid edge fuel rodlet model. 


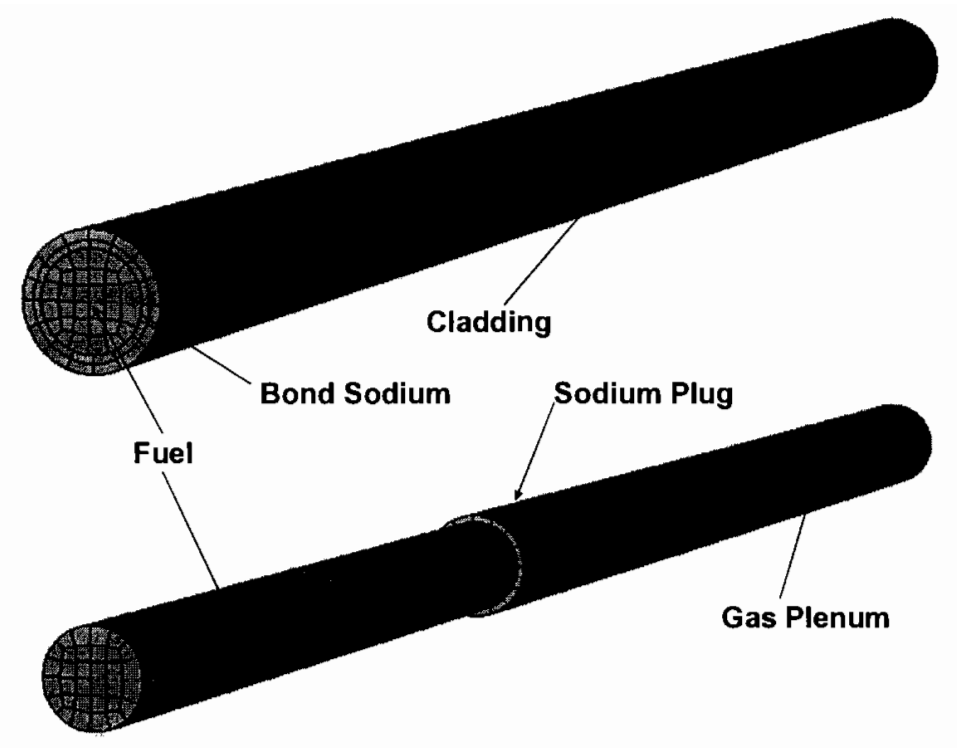

Figure 10. Finite element mesh of assembled fuel rodlet and fuel assembly with the cladding and bond sodium material hidden.

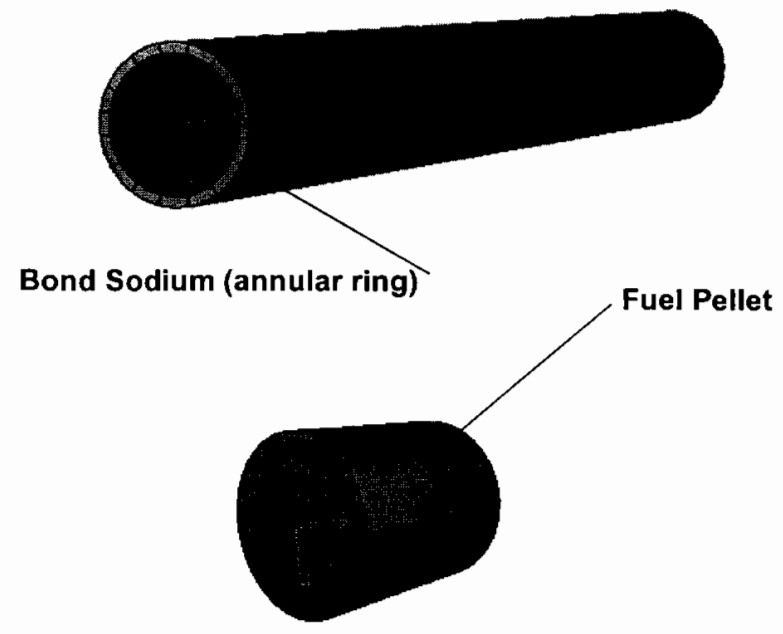

Figure 11. Meshed bond sodium annulus and one fuel pellet. 
can be bias toward one end of the edge, thus creating a denser mesh in regions where the gradient of the temperature or stress is the greatest. For this initial model we used a uniform distribution of seeding.

\section{ABAQUS MATERIAL PROPERTY SUBROUTINES}

In the course of modeling the performance of fuels, one has to be concerned with a large number of phenomena which influences the behavior of the fuel during its lifetime in a radiation environment (nuclear reactor). These phenomena include thermal expansion, creep, fission product swelling, fission gas release, pressurization of the plenum, fuel cracking, fuel temperatures and coolant temperatures to name a few. These phenomena have been model using the FRAPCON code which was design specifically for LWR reactor fuel $\left(\mathrm{UO}_{2}\right)$. However, since the FRAPCON code lacks thermal and mechanical properties corresponding to nitride and metal fuels and the fact that there have been significant developments in solid mechanics especially in the use of finite element methods, we decided to look at fuel modeling of nitride and metal fuels using a finite element code.

The ABAQUS code is a suite of powerful engineering simulation programs based on the finite element method that can solve problems ranging from relatively simple linear analyses to the most challenging nonlinear simulations. In addition to solving structural (stress/displacement) problems it can also simulate problems in the area of heat transfer and mass diffusion. Therefore, we should be able to model a fully coupled thermal stress analysis (including displacement and fuel cladding surface interactions) of the nitride fuel provided we can supply thermal and mechanical properties as well as the appropriate phenomenological models associated with nitride and metal fuel behavior.

The ABAQUS code provide the capability of user subroutines, thus we can integrate appropriate creep and swelling models into ABAQUS by means of the user subroutine CREEP. There are a total of 49 different user subroutines available to the user to define mechanical and thermal loads which develop due to various phenomena associated with fuel behavior in a radiation environment. All of the user subroutines are written as FORTRAN code, thus the subroutines in FRAPCON can be used as examples for writing the appropriate phenomenological models for the nitride and metal fuels.

The required user subroutines are compiled and linked to the ABAQUS code at the start of the execution phase.

\section{ABAQUS FEA ANALYSIS RESULTS}

\section{$8.1 \mathrm{UO}_{2}$ Fuel}

\subsubsection{Thermal Performance}

Since we are using a computer code (ABAQUS) which has very little history of modeling the behavior of nuclear fuels, we developed a simple $\mathrm{UO}_{2}$ fuel model similar to a Los Alamos National Laboratory (LANL) model (see Figure 12). The model shown in Figure 12 was used to help validate the finite element code (FEMLAB) as part of LANL's fuel modeling effort. The model presented in Figure 12 represents a steady state constant property radial heat conduction problem which has an exact analytical solution for both the heat generation and non heat generation regions. This same model is also used to validate the heat conduction capabilities of the ABAQUS code. The analytical solution of the model is presented next. 


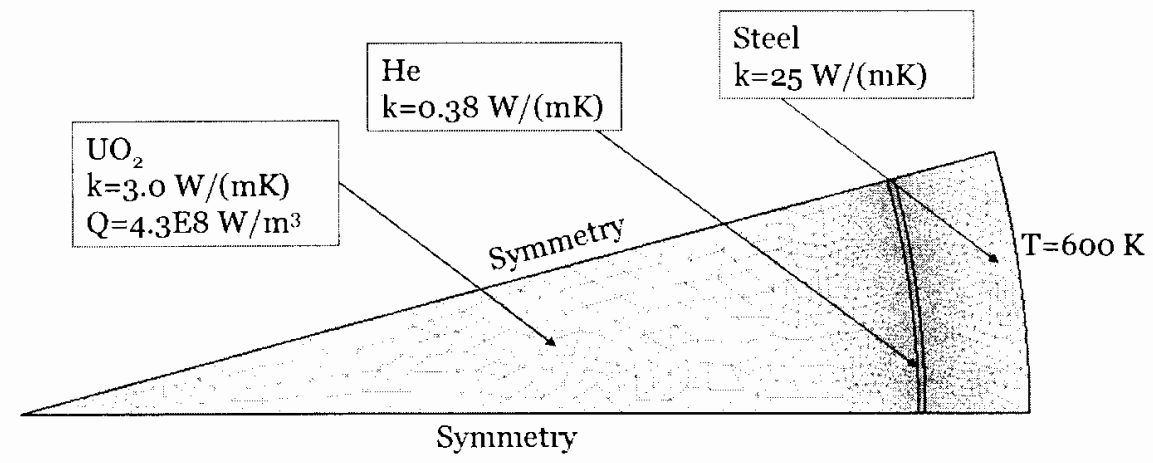

Figure 12. A 2D UO $\mathrm{A}_{2}$ Fuel Rod (wedge) modeled in FEMLAB for comparison with exact solution

The temperature distribution through the helium gap and the cladding is given by Equation (1).

$$
T(r)=\frac{q \cdot \ln \left(r_{2} / r\right)}{2 \cdot \pi \cdot L \cdot k}+T_{2}
$$

where

$$
\begin{array}{lll}
\mathrm{q} & = & \text { the heat transfer rate at the inner surface of the region } \\
\mathrm{r}_{2} & = & \text { the outer radius of the region } \\
\mathrm{T}_{2} & = & \text { the surface temperature at the outer surface of the region } \\
\mathrm{L} & = & \text { the length of the region } \\
\mathrm{k} & = & \text { the thermal conductivity of the region } \\
\mathrm{T}(\mathrm{r}) \quad=\quad & \text { the radial temperature (function of radius) in the region of interest. }
\end{array}
$$

The temperature distribution through the heat generating fuel region is given by Equation (2)

$$
\mathrm{T}(\mathrm{r})=\frac{\dot{\mathrm{q}} \cdot \mathrm{r}_{\mathrm{o}}^{2}}{4 \cdot \mathrm{k}}\left(1-\frac{\mathrm{r}^{2}}{\mathrm{r}_{\mathrm{o}}^{2}}\right)+\mathrm{T}_{\mathrm{s}}
$$

where

$$
\dot{\mathrm{q}}=\quad \text { the volumetric heat generation rate in the fuel }
$$




$$
\begin{aligned}
& \mathrm{r}_{\mathrm{o}}=\text { the outer radius of the fuel } \\
& \mathrm{k} \quad \text { the thermal conductivity of the fuel } \\
& \mathrm{T}_{\mathrm{s}}=\text { the surface temperature at the outer radius of the fuel } \\
& \mathrm{T}(\mathrm{r})=\quad \text { the radial temperature (function of radius) in the fuel. }
\end{aligned}
$$

A comparison of the analytical and numerical solution (generated by ABAQUS) to the above problem is shown below.

The ABAQUS representation of the model for this problem is shown in 13. The model is essentially the same as shown in Figure 12 with the exception that the elements used in the ABAQUS model are different than elements used in the FEMLAB model.

The geometry, thermal properties and boundary conditions used in the $\mathrm{UO}_{2}$ fuel pin modeled are presented in Table 3.

A plot of the radial temperature profile through the UO2 fuel rod is presented in Figure 14 for both the analytical and numerical solution. The maximum predicted fuel centerline temperature for both calculations is $1381 \mathrm{~K}$. As seen the numerical and analytical solutions essentially coincide through out the entire fuel rod, thus $\mathrm{ABAQUS}$ can predict the thermal behavior of fuel rods provided the appropriate thermal properties are known.

\begin{tabular}{|c|c|c|c|c|c|c|c|c|c|c|}
\hline Fuel & $\begin{array}{c}\text { Fuel OD } \\
(\mathrm{m})\end{array}$ & $\begin{array}{c}\text { TC } \\
\text { Fuel } \\
(\mathrm{W} / \mathrm{m}-\mathrm{K}) \\
\end{array}$ & $\begin{array}{c}\text { Volumetric } \\
\text { Heat } \\
\text { Generation } \\
\text { Rate } \\
\left(\mathrm{MW} / \mathrm{m}^{3}\right) \\
\end{array}$ & $\begin{array}{c}\text { Gap } \\
\text { Material }\end{array}$ & $\begin{array}{c}\text { Gap } \\
\text { Thickness } \\
\text { (m) }\end{array}$ & $\begin{array}{c}\mathrm{TC} \\
\mathrm{Gap} \\
(\mathrm{W} / \mathrm{m}-\mathrm{K}) \\
\end{array}$ & $\begin{array}{c}\text { Clad } \\
\text { Material } \\
\end{array}$ & $\begin{array}{c}\text { Clad } \\
\text { Thickness } \\
(\mathrm{m})\end{array}$ & $\begin{array}{c}\mathrm{TC} \\
\text { Clad } \\
(\mathrm{W} / \mathrm{m}-\mathrm{K})\end{array}$ & $\begin{array}{c}\text { Temp } \\
\text { OD } \\
\text { Clad } \\
\left({ }^{\circ} \mathrm{C}\right)\end{array}$ \\
\hline $\mathrm{UO}_{2}$ & 0.008500 & 3.0 & 430.0 & Helium & 0.00005 & 0.38 & Steel & 0.00045 & 25.0 & 327.0 \\
\hline UN & 0.004267 & 8.0 & 2158.8 & Sodium & 0.00033 & 65.0 & Steel & 0.000458 & 22.0 & 487.0 \\
\hline
\end{tabular}

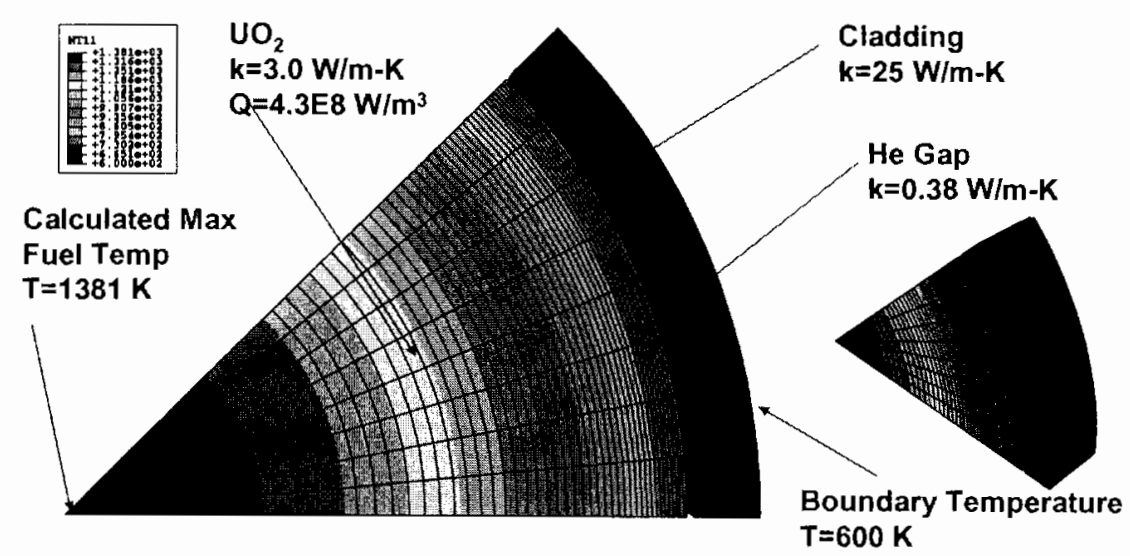

Figure 13. ABAQUS model of 2D fuel rod problem.

Table 3. Parameters used in the models. 


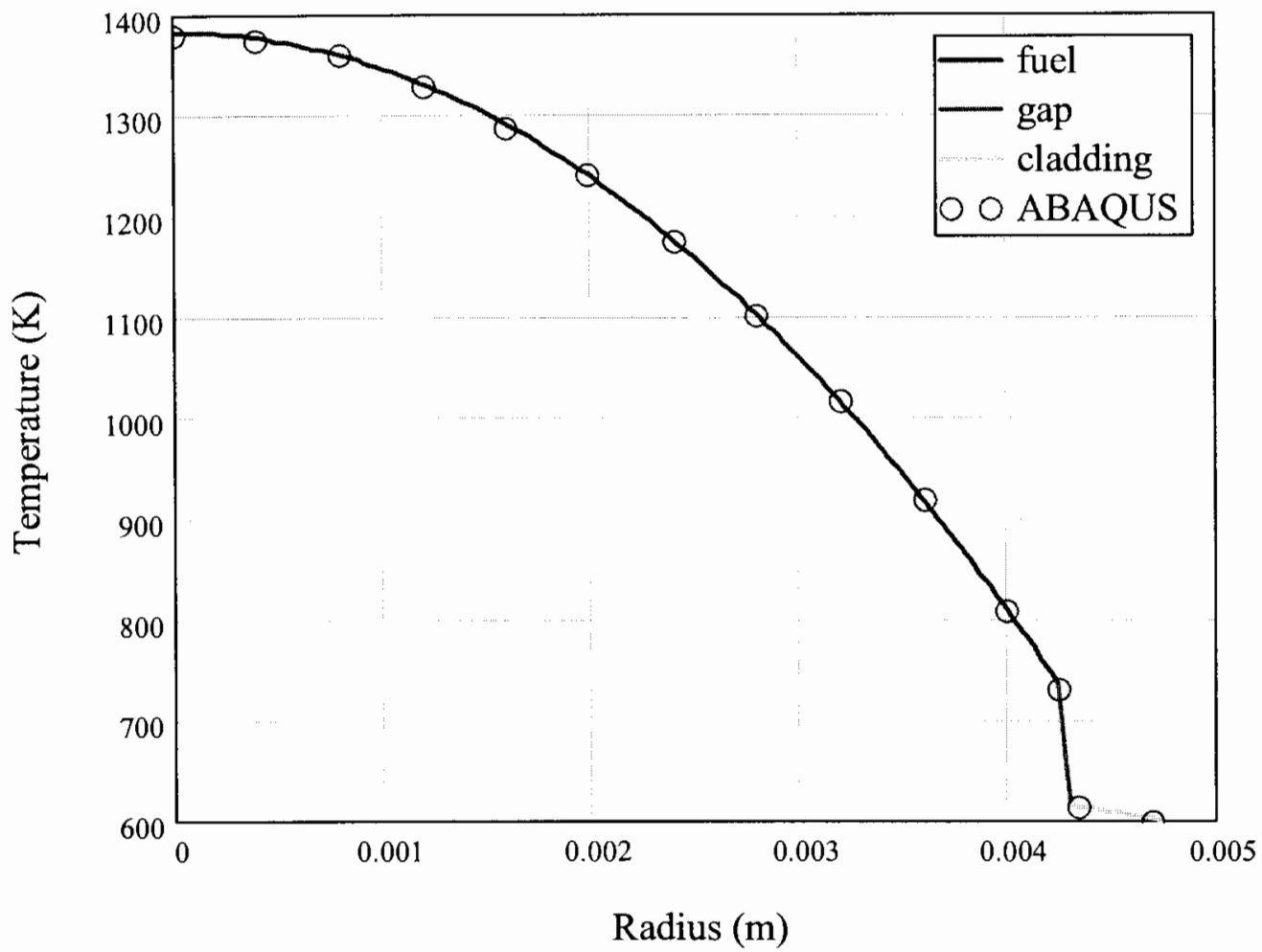

Figure 14. Radial temperature profile through $\mathrm{UO}_{2}$ fuel rod.

For this problem we assumed that the surface temperature on the exterior of the cladding was known. In reality the surface temperature will be a function of the coolant mass flow rate, thermal properties of the fluid, and the heat generation in the fuel pin. Although ABAQUS does not have CFD capabilities built into the code it now can be coupled to a CFD code such as FLUENT which can solve the fluid mechanics part of the problem and send the appropriate information back to ABAQUS.

\subsection{UN Fuel}

\subsubsection{Thermal performance}

Before a full Uranium Nitride (UN) fuel rod as shown in Figure 3 can be analyzed, it is necessary that one understand the thermal and mechanical coupling that occurs in a small section of the fuel pin (one pellet, bond sodium, and cladding). This coupling can include mechanisms such as fuel and cladding deformation, rod internal gas pressure, and fuel swelling to name a few. Assuming azimuthal symmetry, a quarter section of one fuel pellet and it surrounding structure (bond sodium and cladding) was modeled. The model is a representation of a small section of a UN fuel pin tested in the ATR reactor (AFC-1C rodlet 4). The finite element model and a contour temperature plot are shown in Figure 15. The rodlet geometry, thermal properties, and volumetric heat generation rate are listed in Table 3.

The maximum centerline temperature predicted by ABAQUS for the listed conditions is $1117 \mathrm{~K}$ which corresponds to the analytical solution as shown in Figure 16. Viewing Figure 16 we see that radial temperatures through the fuel rodlet predicted by the ABAQUS model coincide exactly with the analytical generated temperature profile obtained using Equations (1) and (2). The second solid line curve 
presented in Figure 16 is the radial temperature profile through the fuel rodlet using the temperature dependent thermal conductivity shown in Figure 17. The maximum fuel rodlet centerline temperature for this case is $960 \mathrm{~K}$.

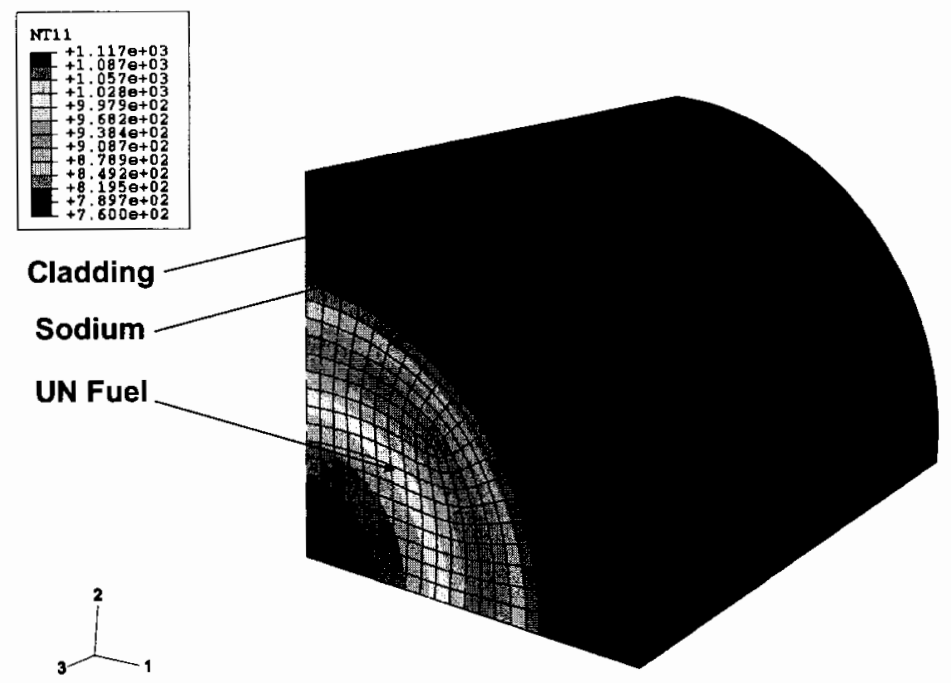

Figure 15. Contour temperature plot of UN fuel model.

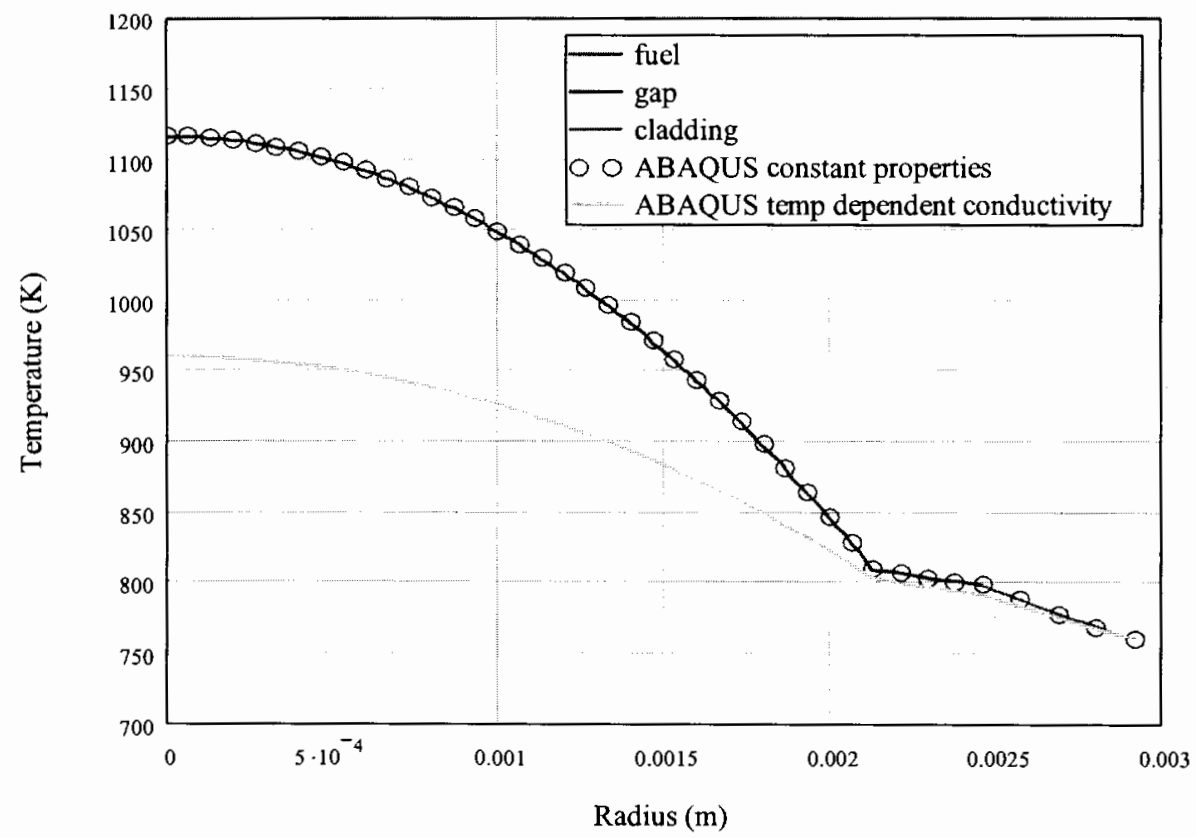

Figure 16. Radial temperature profile through UN fuel rodlet. 


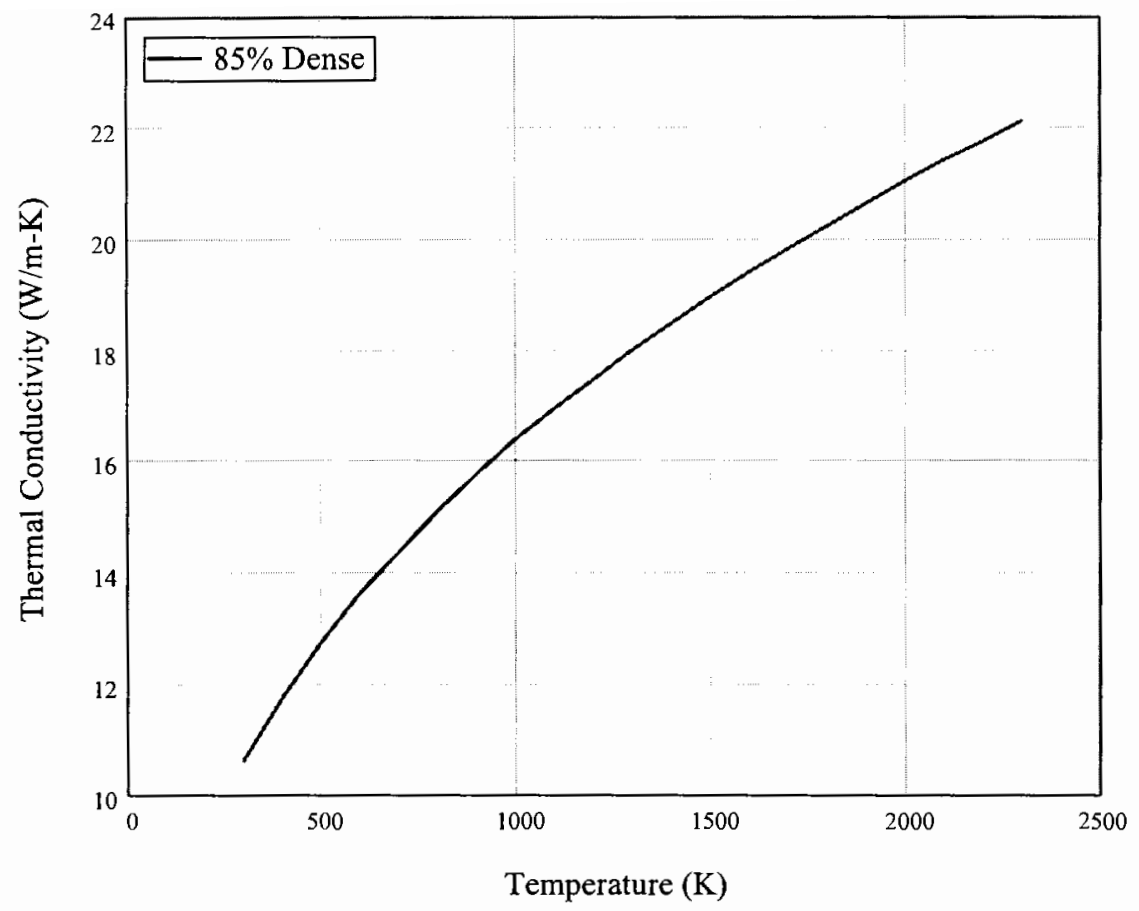

Figure 17 . Temperature dependent UN thermal conductivity.

The average temperature of the bond sodium in the gap between the fuel and cladding for both cases present in Figure 16 is approximately $800 \mathrm{~K}$. The melting temperature of sodium is $371 \mathrm{~K}$, thus the bond sodium material for this case is molten.

The thermal conductivity curve presented in Figure 17 was generated using the following equation (see Section 2.3.12)

$\mathrm{k}=1.864 \cdot \exp (-2.14 \cdot \mathrm{P}) \cdot \mathrm{T}^{0.361}$

where

$\mathrm{P}=$ the porosity of the fuel

$\mathrm{T}=$ the temperature in degrees Kevin.

Equation (3) was obtained from Reference 2. The porosity of the AFC-1C rodlet 4 was listed as $15 \%$ in Reference 1.

\subsubsection{Mechanical behavior}

Next we looked at the effect that the thermal expansion of the fuel would have on the deformation of the fuel and cladding. The following thermal expansion coefficient for UN fuel as a function of temperature (see Figure 18) was input into the ABAQUS model. The functional relationship for the thermal expansion coefficient was obtained from Reference 3 and is shown below as Equation 4. (see Section 2.3.14)

$\alpha=7.096 \cdot 10^{-6}+1.409 \cdot 10^{-9} \cdot \mathrm{T}$ 
A preliminary assessment of the results show that the molten sodium is being squeeze out the end of the fuel rod as shown in Figures 19 and 20. This is due to the closing of the gap between the fuel and cladding as the fuel expands. Viewing Figure 19, we see that the sodium is only being extruded out the left end of the fuel rodlet model. Since the model is symmetric in the longitudinal direction one would expect that the sodium would be extruded out both ends of the model, thus it appears that a boundary constraint was not applied correctly. This will be corrected as we learn more about applying the powerful modeling capabilities of ABAQUS to the problem of modeling fuel behavior.

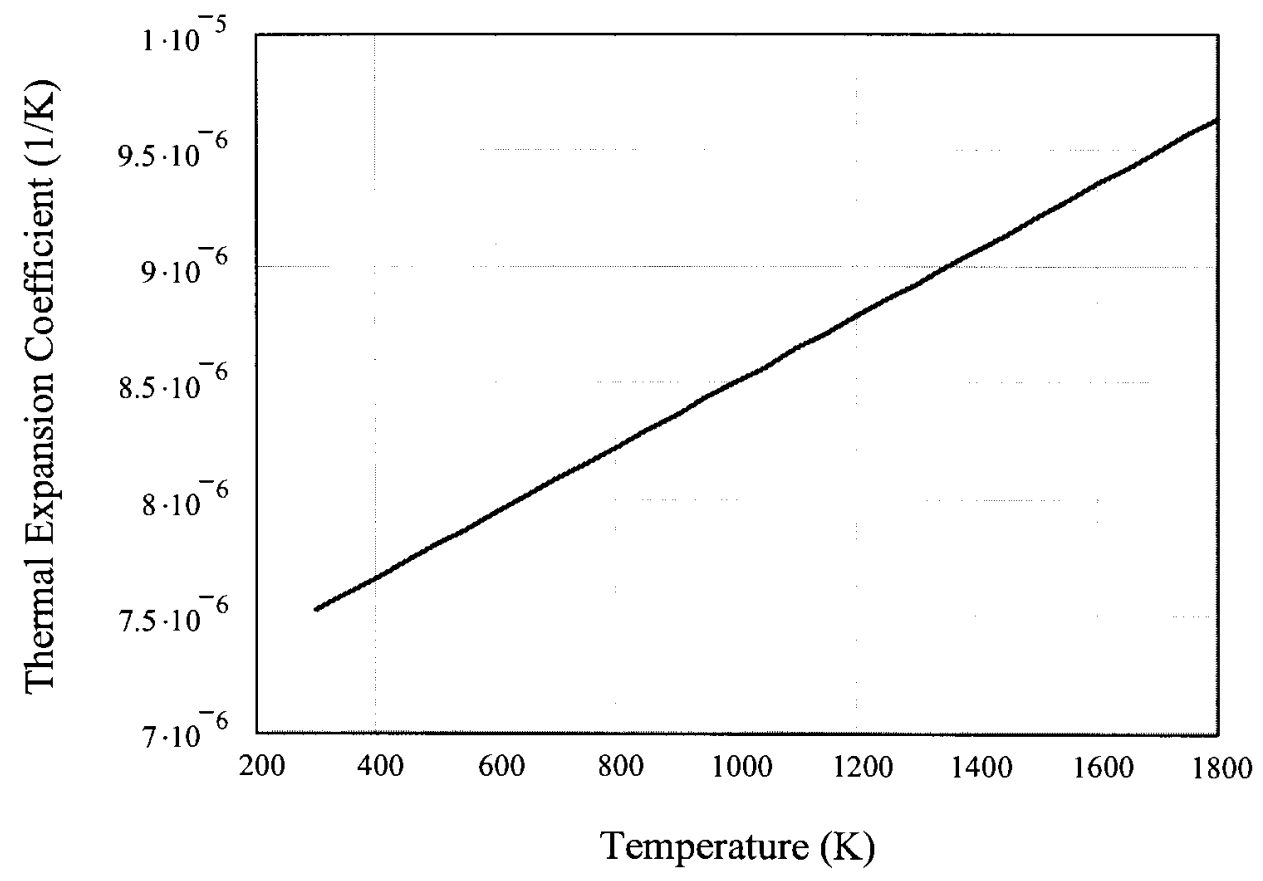

Figure 18. Uranium Nitride temperature dependent thermal expansion coefficient.

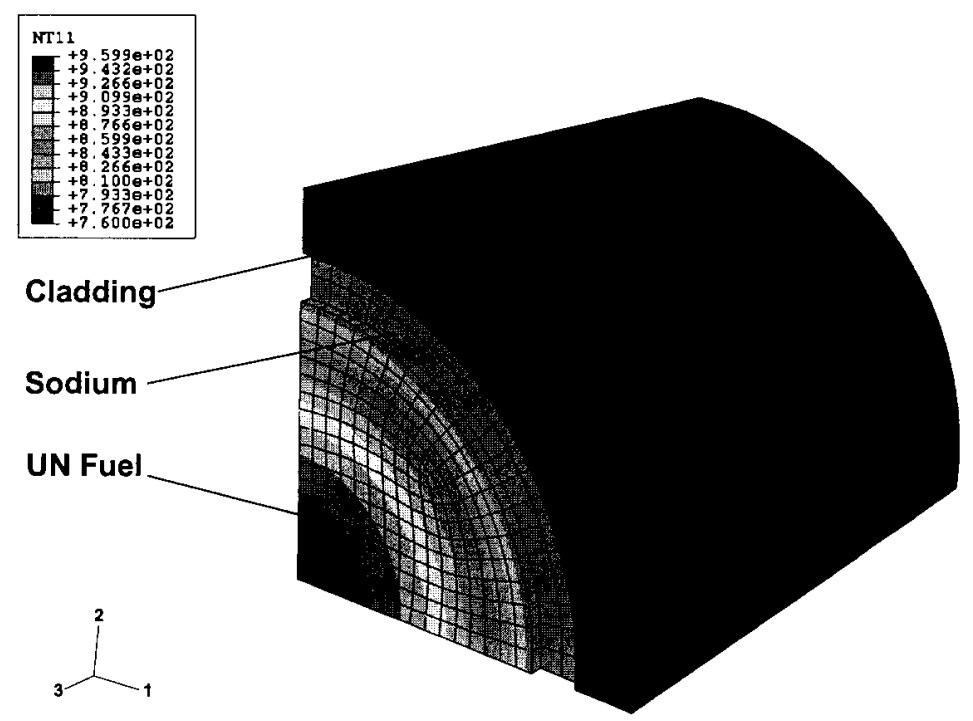

Figure 19. Isometric view of deformed fuel rodlet. 


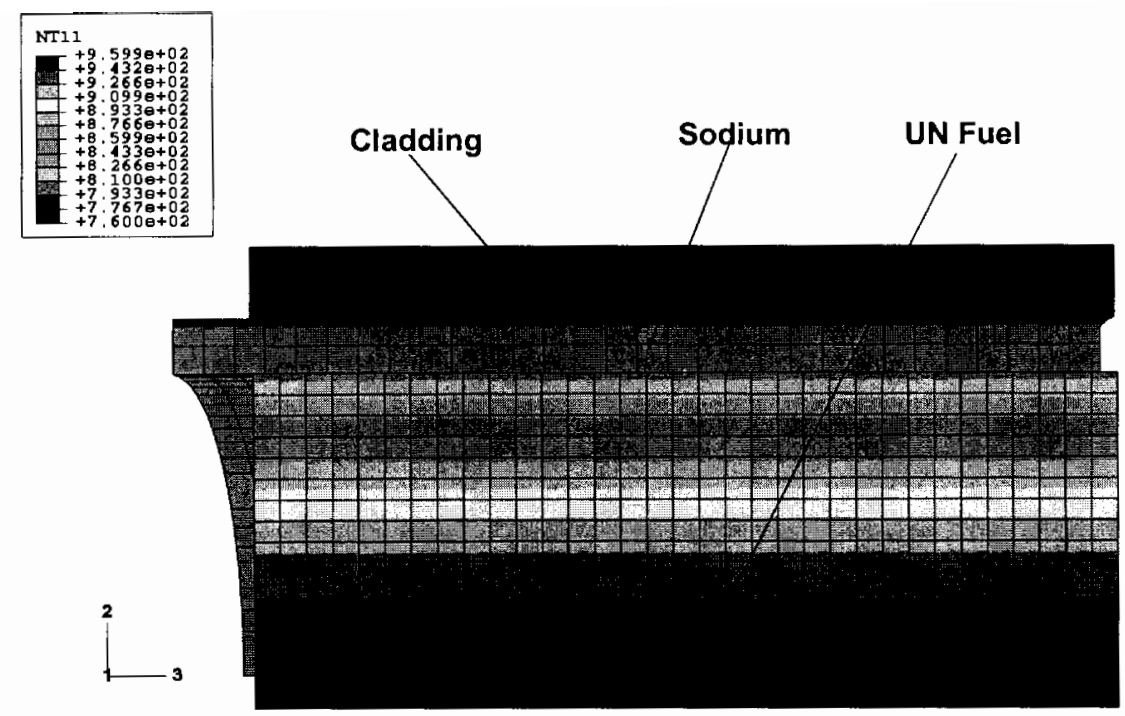

Figure 20. Side view of the deformed rodlet.

\subsection{Discussion of Weaknesses in Material Property Data Base Relative to the Fuel Behavior and Performance}

The purpose of this effort was to provide the basis for a model that effectively predicts nitride fuel behavior. Material property models developed for the uranium nitride fuel system have been used to approximate the general behavior of nitride fuels with specific property models for the transuranic nitride fuels utilized as they become available. The AFCI fuel development program now has the means for predicting the behavior of the transuranic nitride fuel compositions. The key data and models needed for input into this model include:

- Thermal conductivity with burnup

- $\quad$ Fuel expansion coefficient

- $\quad$ Fuel swelling with burnup

- $\quad$ Fission gas release with burnup.

It is important to note that although the fuel performance model is a fully functional FEA analysis tool, it is limited by the input data and models.

\section{REFERENCES}

1. Hayes, S. L., W7520-0481-ES-02, Irradiation of Nitride and Metallic Fuels for Actinide Transmutation in the Advanced Test Reactor, Argonne National Laboratory Feb. 19, 2003

2. Hayes, S. L., J. K. Thomas and K. L. Peddicord, Material Property Correlations for Uranium Mononitride III Transport properties, J. Nucl. Mater., 171, 289, 1990.

3. Hayes, S. L., J. K. Thomas and K. L. Peddicord, Material Property Correlations for Uranium Mononitride I Physical properties, J. Nucl. Mater., 171, 262, 1990. 


\section{GLOSSARY}

Bulk Modulus: The ratio of pressure to the decrease in volume, the inverse of compressibility

Creep: Time dependent, permanent deformation at high temperatures, occurring at constant load or constant stress

Critical Temperature: temperature above which a substance cannot exist as a liquid no matter how great a pressure is applied

Density: Mass per unit volume

Diffusion Coefficient: The constant which is a measure of how well a dissolved material can diffuse through a concentration gradient, depends on particle size of materials, temperature, and polarity

Enthalpy: A thermodynamic quantity equal to the internal energy of a system plus the product of its volume and pressure, the amount of energy in a system capable of doing mechanical work

Entropy: A thermodynamic state property that measures the degree of disorder or randomness of a system

Electrical Resistivity: The electrical resistance offered by a material to the flow of current, times the cross-sectional area of current flow and per unit length of current path; the reciprocal of the conductivity

Gas Release: Percentage of gas produced in the material matrix due to irradiation that is released from the material matrix.

(Gibb's) Free Energy of Formation (Free Energy Function): Thermodynamic state function of a system that indicates the amount of energy available for the system to do useful work at constant temperature and pressure

Hardness: Resistance of a material to penetration by a sharp object

Heat Capacity: Amount of heat required to raise the temperature of a body (of whatever mass) one degree Celsius

Heat of Formation: Enthalpy change in which the number of moles or reactants specified in the balanced chemical equation, all standard states, is converted completely to the specified number of moles of products, all at standard states

Heat of Fusion: Amount of heat required to melt a specific amount of solid at its melting point with no change in temperature (usually expressed in $\mathrm{J} / \mathrm{g}$ )

Heat of Sublimation: The heat absorbed by a unit of mass of material when it changes from a solid state to a gaseous state

Heat of Vaporization: Amount of heat required to vaporized a specific amount of liquid at its boiling point with no change in temperature (usually expressed in $\mathrm{J} / \mathrm{g}$ )

Lattice Parameter: The length of the sides of the unit cell and the angles between those sides, describe the size and shape of the unit cell.

Linear Coefficient of Thermal Expansion: Describes the amount by which each unit length of a material changes when the temperature of the material changes by one degree

Melting Point: Temperature at which liquid and solid coexist in equilibrium

Modulus of Elasticity: Slope of stress-strain curve in the elastic region (E), also know as Young's Modulus

Modulus of Rigidity: Shear or torsion modulus, proportionality coefficient between stress and strain in pure shear, derived from the Modulus of Elasticity $(2 \mathrm{G}=\mathrm{E} /(1+\mathrm{n}))$

Poisson's Ratio: Ratio between the lateral and longitudinal strains in the elastic region

Porosity: A phenomena that is observed when two diffusing atom forms move with greatly different rates during diffusion that voids (or pores) form in the region of the diffusion zone from which there is a flow of mass, directly connected with the vacancy motion associated with diffusion in metals, caused by gas evolution during freezing and the shrinkage in volume which accompanies the solidification of most metals

Specific Heat: The heat capacity per unit mass, the amount of heat energy required to raise the temperature of one kilogram of a substance by on Kelvin 
Swelling: percentage of volume increase during irradiation exposure of the material matrix.

Thermal Conductivity: A microstructure-sensitive property that measures the rate at which heat is transferred through a material

Thermal Emission: Emission of photons from a material due to excitation of the material by heat Thermal Expansion: The expansion of a material as a result of the addition of heat

Vapor Pressure: Partial pressure of a vapor in equilibrium with its parent liquid or solid 